Supporting Information for:

\title{
Templating Gold Nanoparticles on Nanofibers Coated with a Block Copolymer Brush for Nanosensor Applications
}

\author{
Hu Zhu, Jean-François Masson, ${ }^{*}$ C. Geraldine Bazuin* \\ Département de chimie, Université de Montréal, C.P. 6128 Succ. Centre-ville, Montréal, QC, \\ Canada H3C 3J7 \\ *Emails: jf.masson@umontreal.ca, geraldine.bazuin@umontreal.ca
}




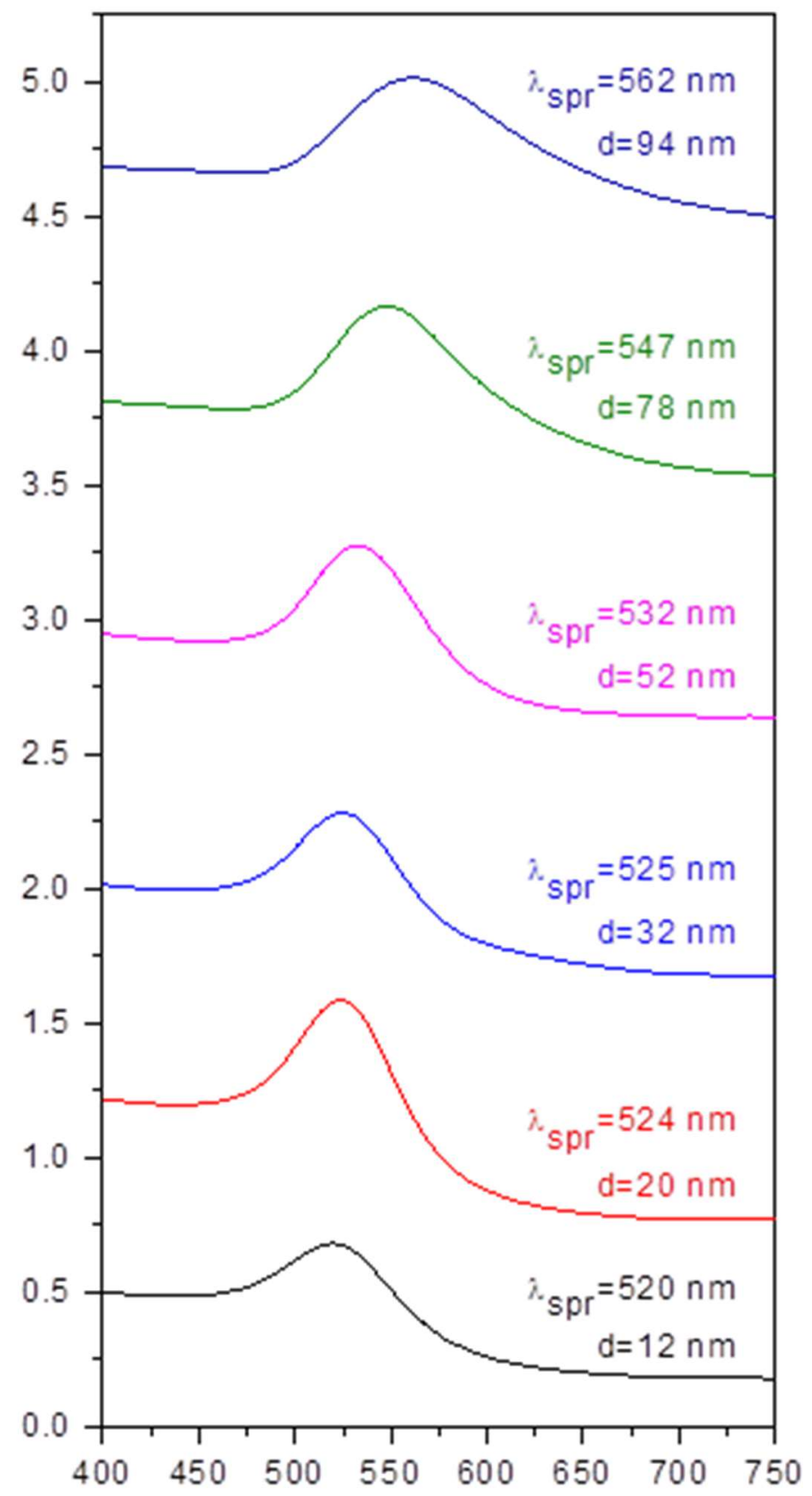

Figure S1. UV-visible spectra of the aqueous suspensions of the AuNPs synthesized, after $\mathrm{pH}$ adjustment, with the measured surface plasmon resonance wavelengths, $\lambda_{\text {spr }}$, and the AuNP diameters, $\mathrm{d}$, derived using the procedure of Haiss et al. ${ }^{1}$ 

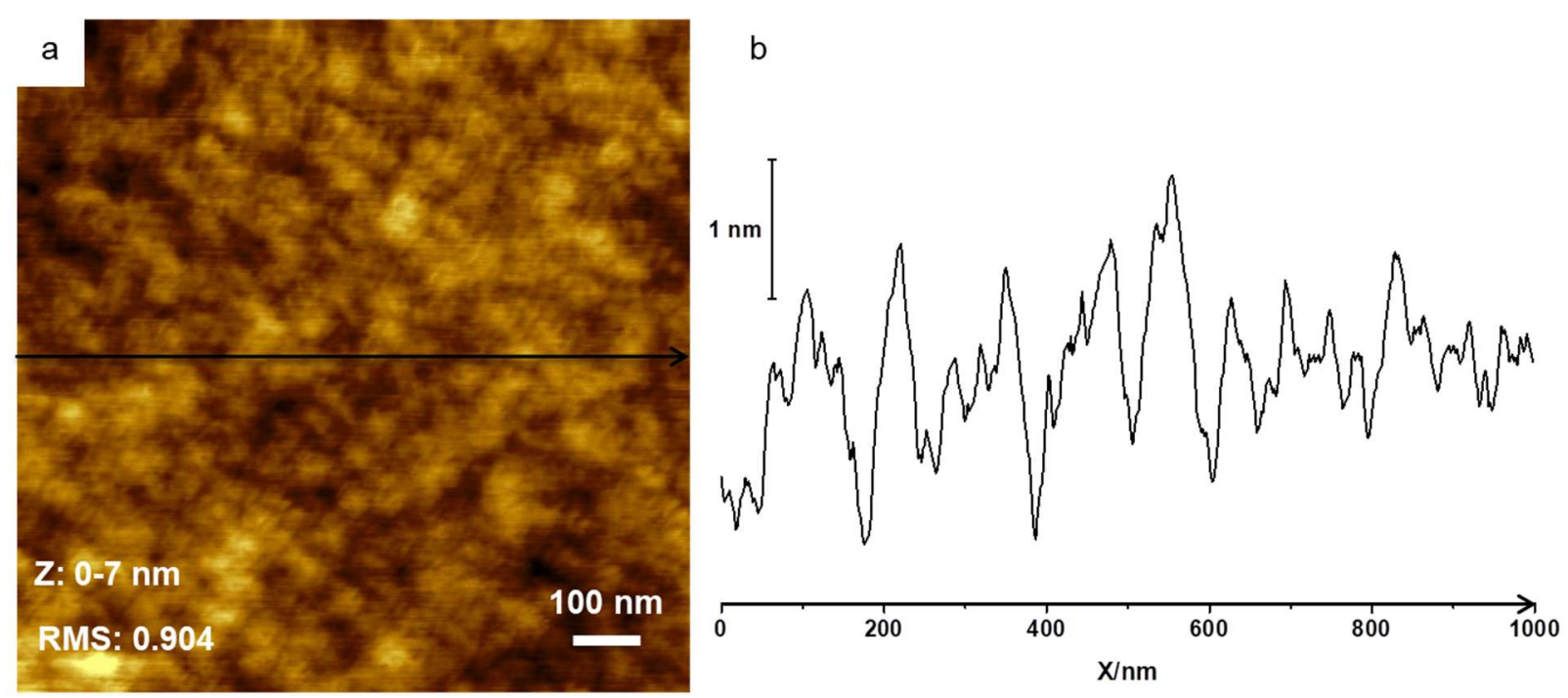

Figure S2. (a) AFM height image of the surface of a bare pulled glass fiber (treated in a piranha solution) at a fiber diameter of about $10 \mu \mathrm{m}$ ( $\mathrm{Z}$ indicates the height scale and RMS the 2D rootmean-square surface roughness). (b) Height profile corresponding to the line drawn in $\mathbf{a}$. 


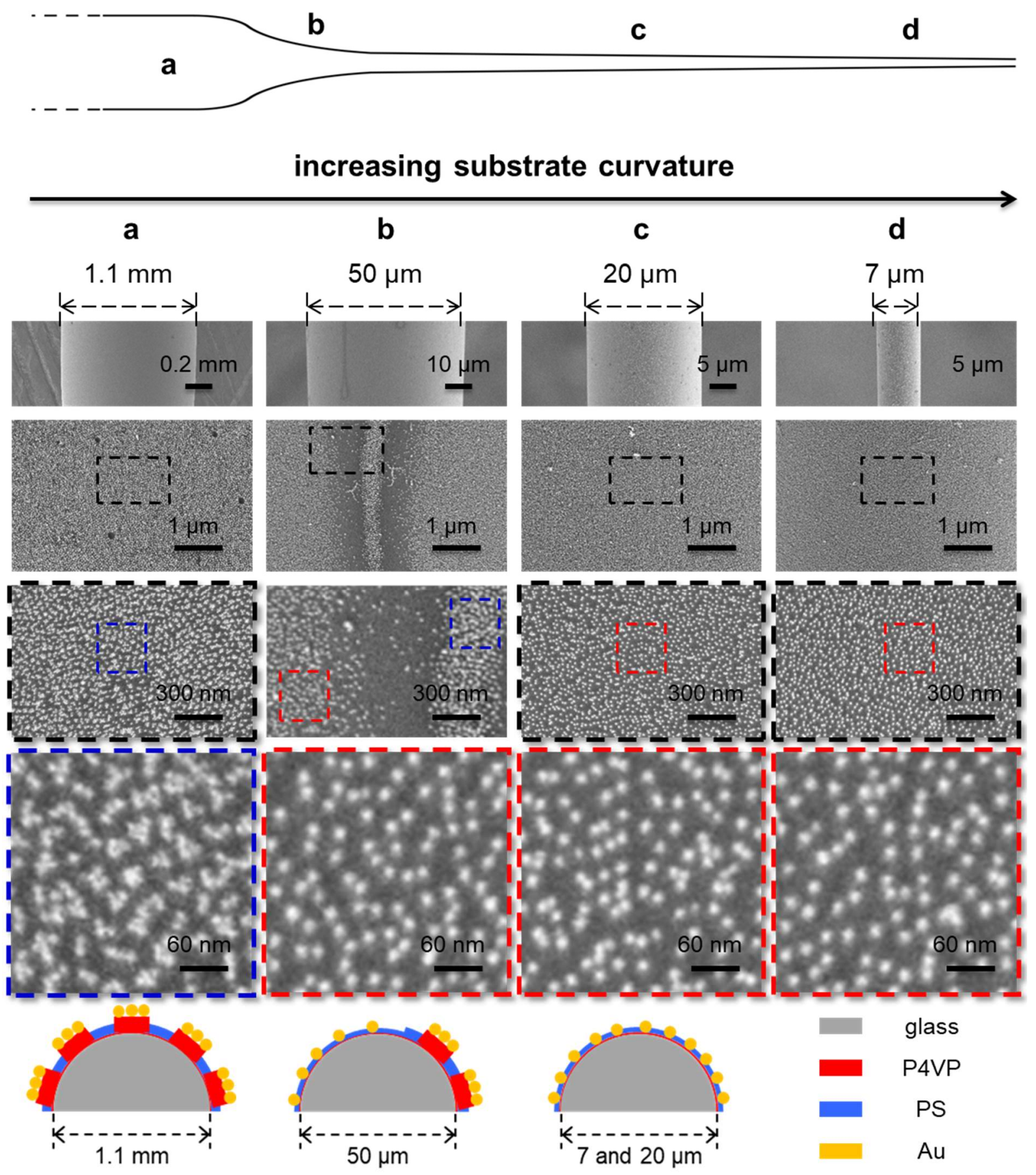

Figure S3. SEM images (various magnifications, indicated by the scale bars) and corresponding schematic models of different regions of a pulled fiber coated with a $\mathrm{PS}_{41}-b-\mathrm{P}_{4} \mathrm{VP}_{20}$ film onto which $12 \mathrm{~nm}$ AuNPs were deposited. The BCP film templates were obtained by the dip-coating procedure using a $20 \mathrm{mg} / \mathrm{mL}$ THF solution and a withdrawal rate of $10 \mathbf{~ m m} / \mathbf{m i n}$. The fiber regions represent (a) the unpulled part of the fiber (low curvature), (b) the pulled fiber neck (rapidly changing curvature), and (c) and (d) pulled parts (relatively high curvature). 


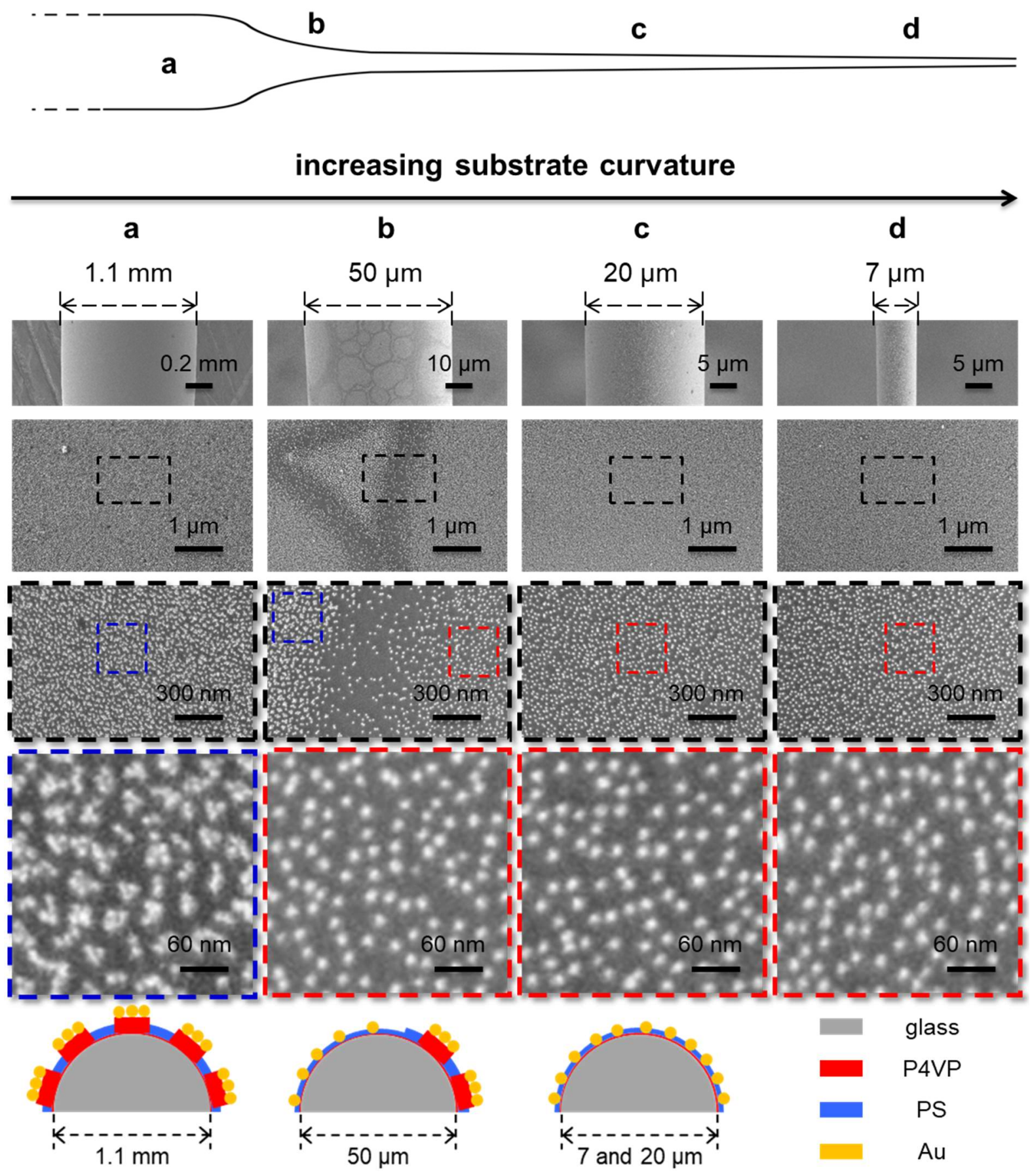

Figure S4. SEM images (various magnifications, indicated by the scale bars) and corresponding schematic models of different regions of a pulled fiber coated with a $\mathrm{PS}_{41}-b-\mathrm{P} 4 \mathrm{VP}_{20}$ film onto which $12 \mathrm{~nm}$ AuNPs were deposited. The BCP film templates were obtained by the dip-coating procedure using a $20 \mathrm{mg} / \mathrm{mL}$ THF solution and a withdrawal rate of $\mathbf{8 0 ~} \mathbf{~ m m} / \mathbf{m i n}$. The fiber regions represent (a) the unpulled part of the fiber (low curvature), (b) the pulled fiber neck (rapidly changing curvature), and (c) and (d) pulled parts (relatively high curvature). 


\section{increasing substrate curvature}

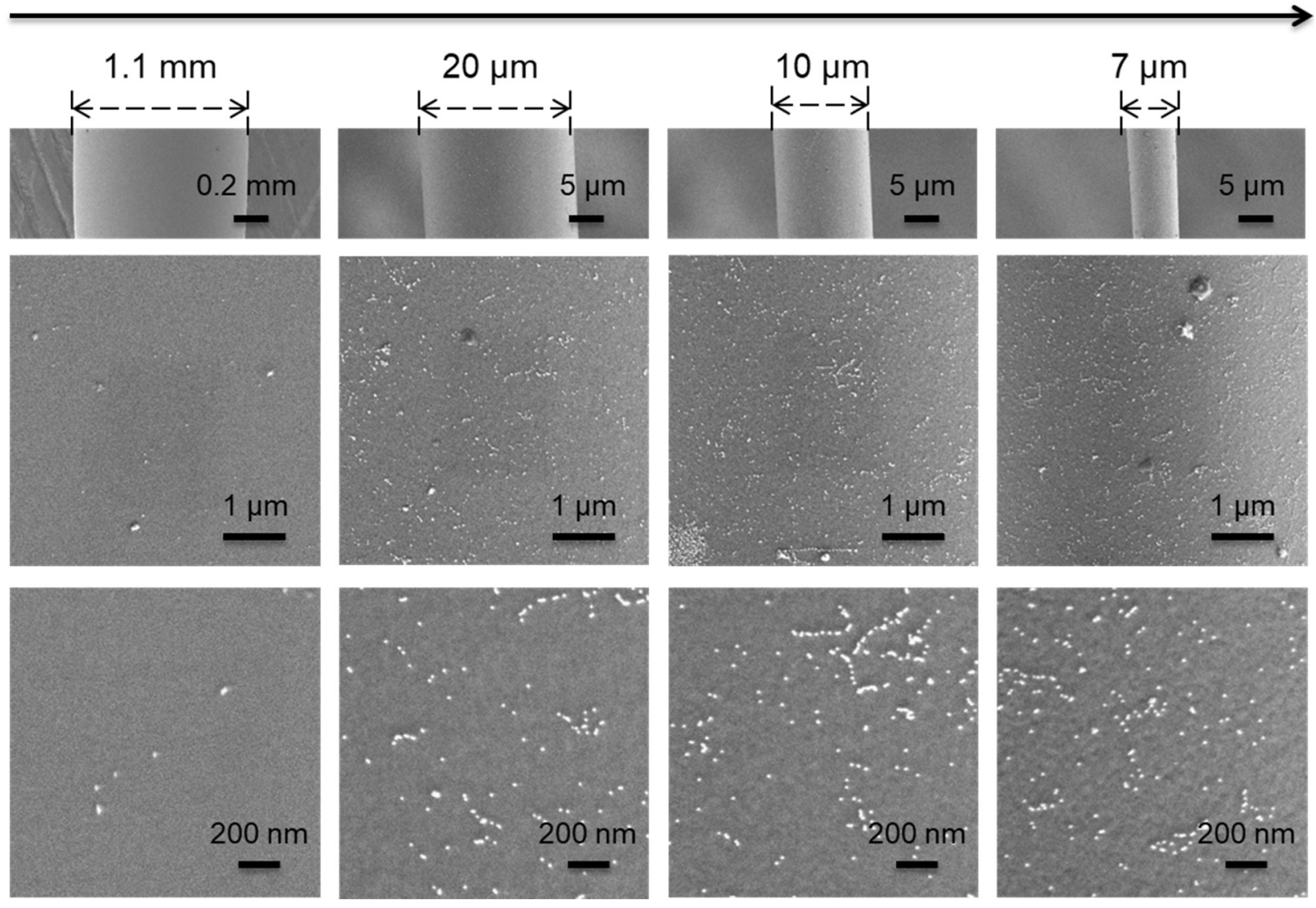

Figure S5. SEM images of a bare pulled glass fiber after piranha bath treatment at various fiber diameters following $2 \mathrm{~h}$ of incubation in a $12 \mathrm{~nm}$ AuNP colloid. 

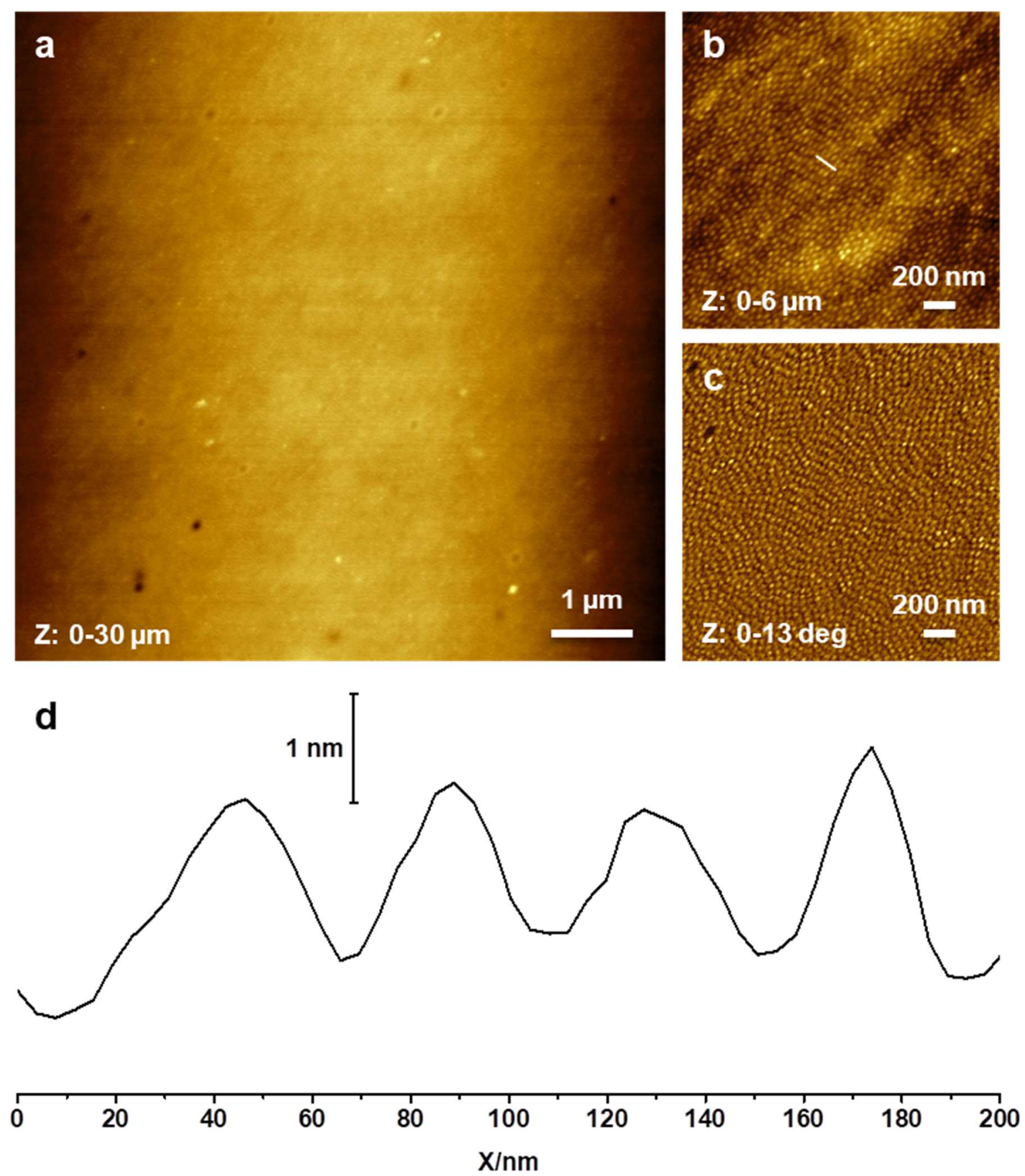

Figure S6. AFM height (a and b) and phase (c corresponding to b) images of a BCP film on a glass fiber at a diameter of $1.1 \mathrm{~mm}$. The film was dip-coated at a withdrawal rate of $0.5 \mathrm{~mm} / \mathrm{min}$ from a $20 \mathrm{mg} / \mathrm{mL} \mathrm{PS}_{41}-b-\mathrm{P}_{4} \mathrm{VP}_{20} / \mathrm{THF}$ solution. The height profile (d) along the line drawn in (a) indicates that the average center-to-center distance between dots is about $35 \mathrm{~nm}$ and the dot diameter is about $30 \mathrm{~nm}$. 

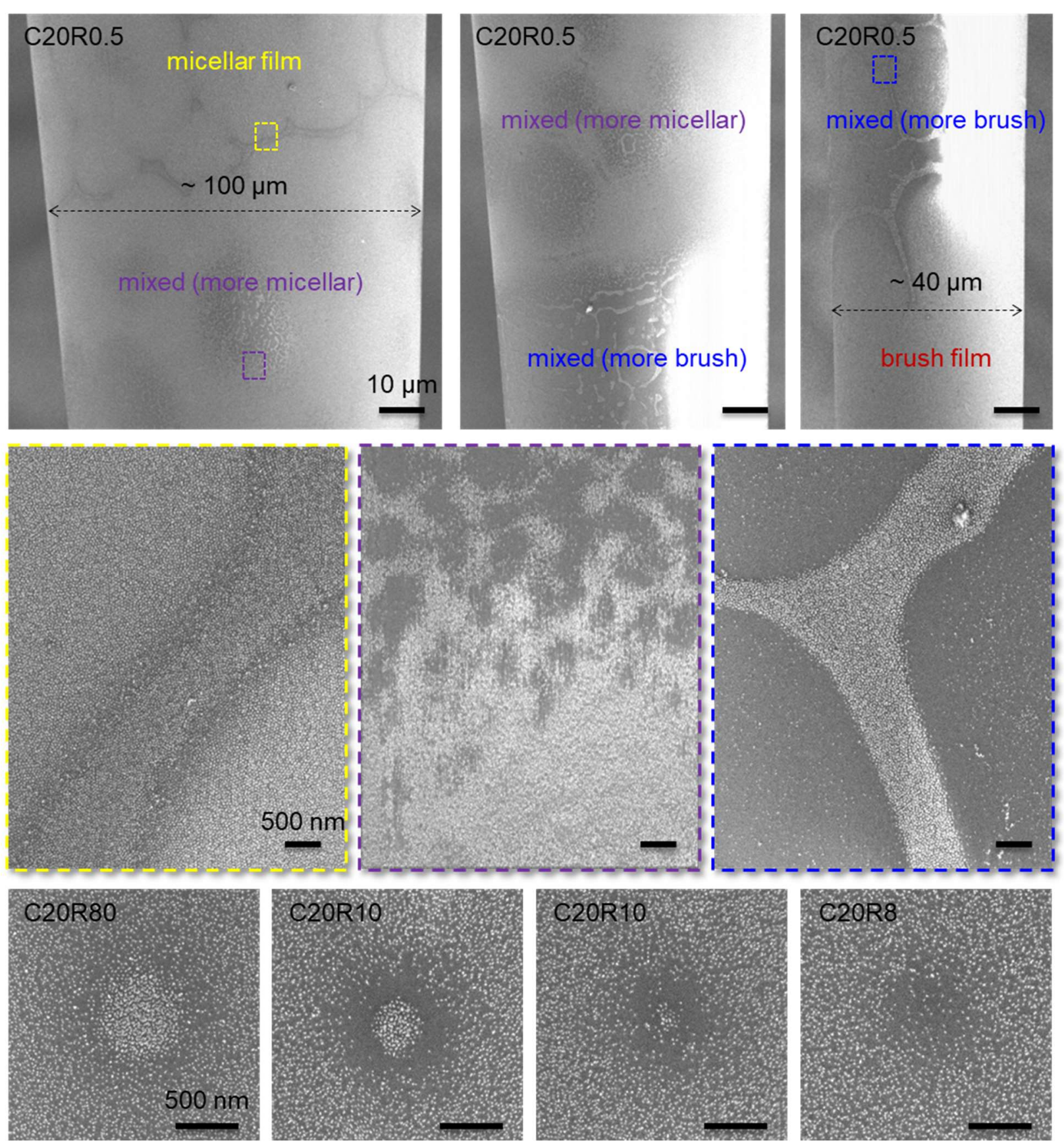

Figure S7. SEM images of fibers after the deposition of $12 \mathrm{~nm}$ AuNPs on BCP templates prepared from a THF solution of $20 \mathrm{mg} / \mathrm{mL} \mathrm{PS} 41-b-\mathrm{P}_{4} \mathrm{VP}_{20}(\mathrm{C} 20)$ at the dip-coating withdrawal rates indicated ( $\mathrm{R}$ in $\mathrm{mm} / \mathrm{min}$ ). Top row: Low-resolution images showing the transitioning of the template with decreasing substrate diameter from a pure micellar form, to a mixture of micellar and brush zones (ranging from more micellar to more brush), to a pure brush form. The very bright areas on the right side of the fibers is caused by electron charging during SEM. Middle row: High 
resolution images of the zones indicated by the color-coded boxes in the top row images (from left to right: full micellar, mixed zone of more micellar and less brush, mixed zone of dewetted micellar and more brush). In the two rightmost images, the (darker) brush zones show relatively little AuNP deposition and are thus also termed "depletion zones", which we typically observe in the vicinity of micellar zones. In the leftmost image of both the top and middle row, the darker traits contain AuNP clusters and therefore are micellar (albeit less dense) and were observed only with the C20R0.5 dip-coating conditions, which lead to thicker films than do the other conditions used; we therefore suspect that they may be related to dewetted zones of a second layer of micelles, as shown and explained in ref 2, and that may experience lower electron conductivity due to its greater thickness. Bottom row: High-resolution images of residual dots of cluster zones in dominant brush-layer zones (three leftmost images) and a "depleted zone" dot (rightmost image). 

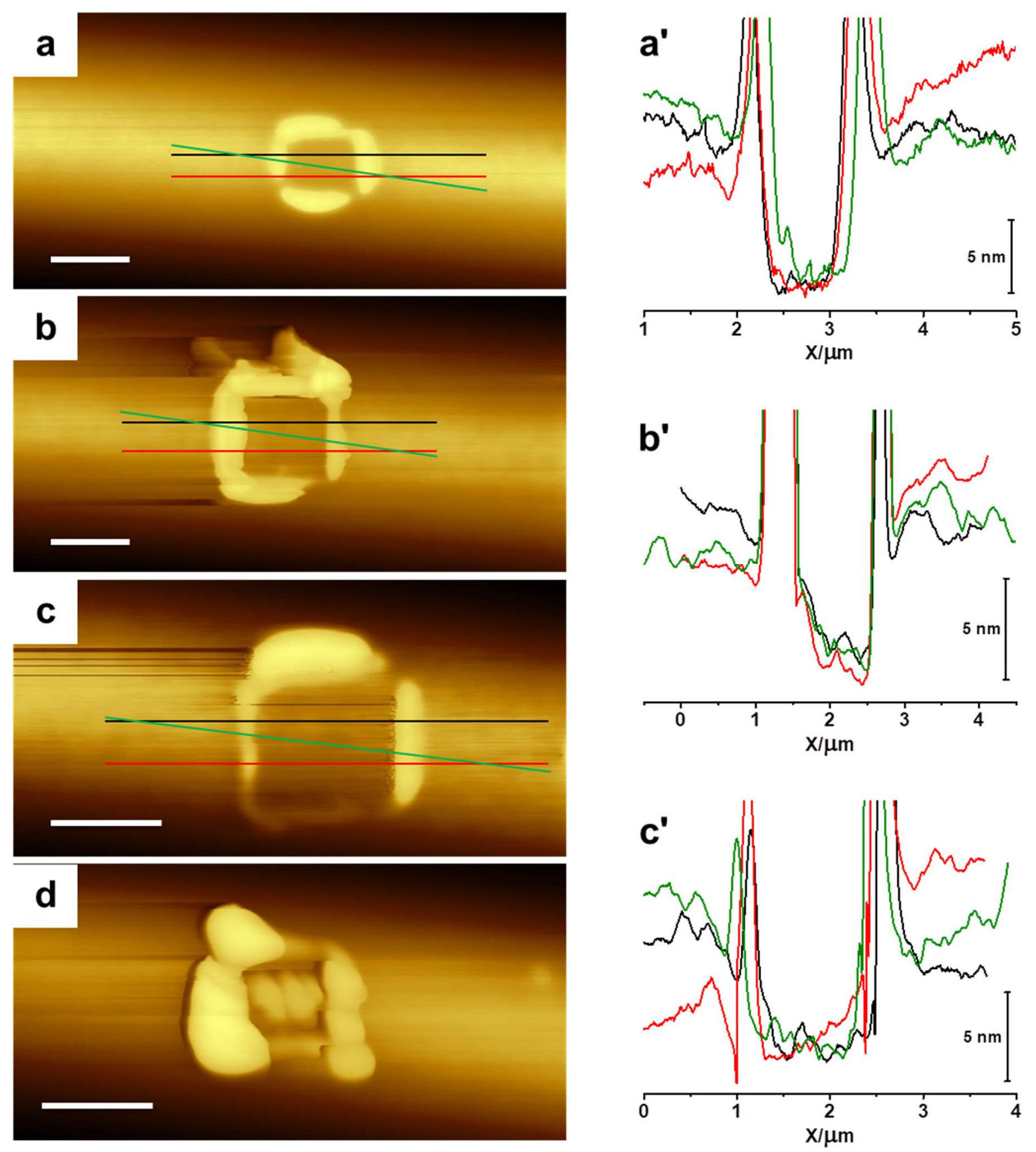

Figure S8. Left, AFM height images (tapping mode, scale bar $1 \mu \mathrm{m}$ ) of three examples of AFM tip-erased (contact mode) areas on pulled fibers at diameters of 10-30 $\mu \mathrm{m}$, where the fibers were coated with a $\mathrm{PS}_{41}-b-\mathrm{P}_{4} \mathrm{VP}_{20}$ brush film using polymer solution concentrations of (a) $0.05 \mathrm{mg} / \mathrm{mL}$, (b) $5 \mathrm{mg} / \mathrm{mL}$ and (c) $20 \mathrm{mg} / \mathrm{mL}$, with (d) showing an example of a rejected erasure experiment. Right, height profiles whose colors correspond to the lines drawn in (a), (b) and (c). 


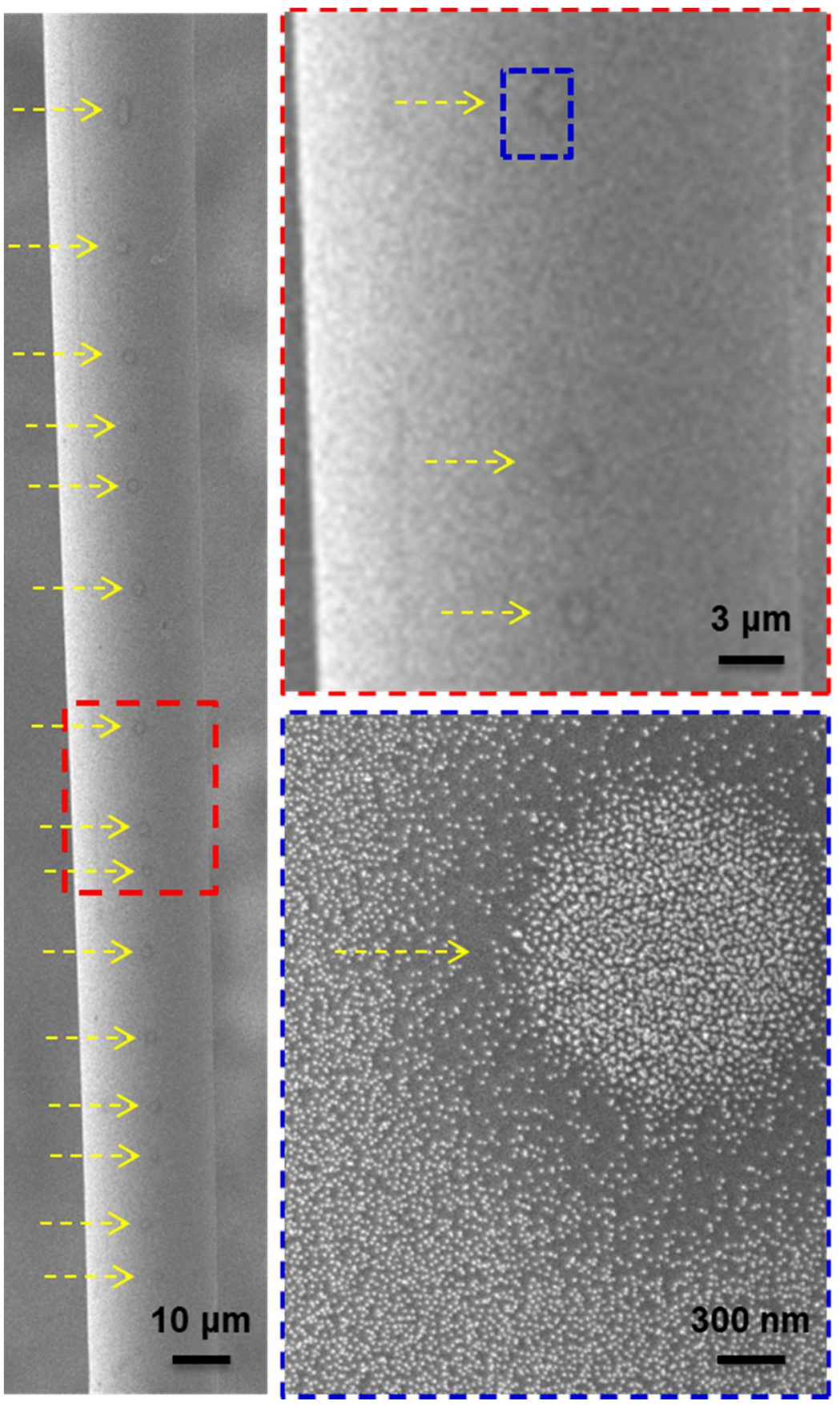

Figure S9. SEM images of a fiber, in the lower fiber diameter range of the dewetted region, after the deposition of $12 \mathrm{~nm}$ AuNPs using a $\mathrm{PS}_{41}-b-\mathrm{P}_{4} \mathrm{VP}_{20}$ film template dip-coated at $80 \mathrm{~mm} / \mathrm{min}$ from a $20 \mathrm{mg} / \mathrm{mL}$ BCP solution. A series of droplet-like dewetted micellar regions along the fiber length, suggestive of a Plateau-Rayleigh instability, are indicated by yellow arrows in the left image, three of which are expanded in the top right image and one shown at high resolution in the bottom right image. 

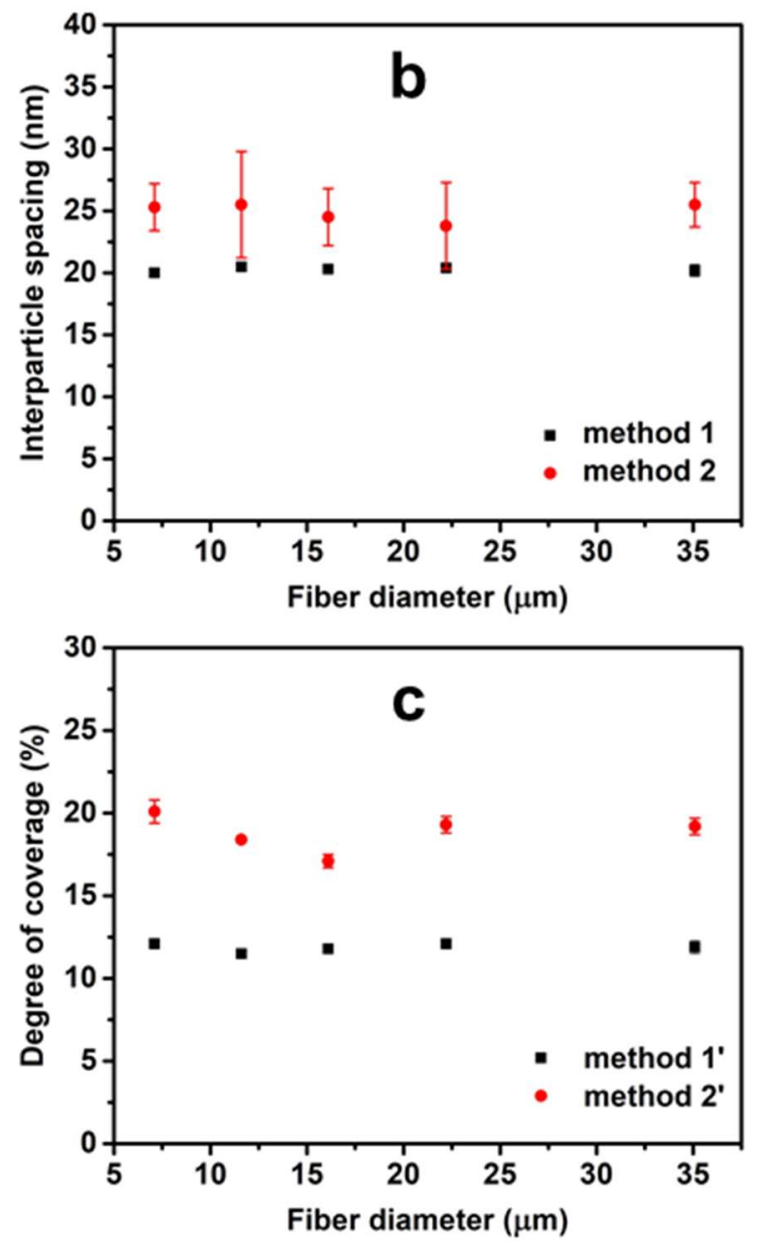

Figure S10. Graphs complementing Figure 4a in the main text. (b) Average interparticle spacing (gap size) and (c) surface coverage of the $12 \mathrm{~nm}$ AuNPs deposited using the BCP brush prepared at $\mathrm{C} 0.05 \mathrm{R} 40$ as a function of fiber diameter. See the experimental section in the main text for details about the methods of analysis used. 


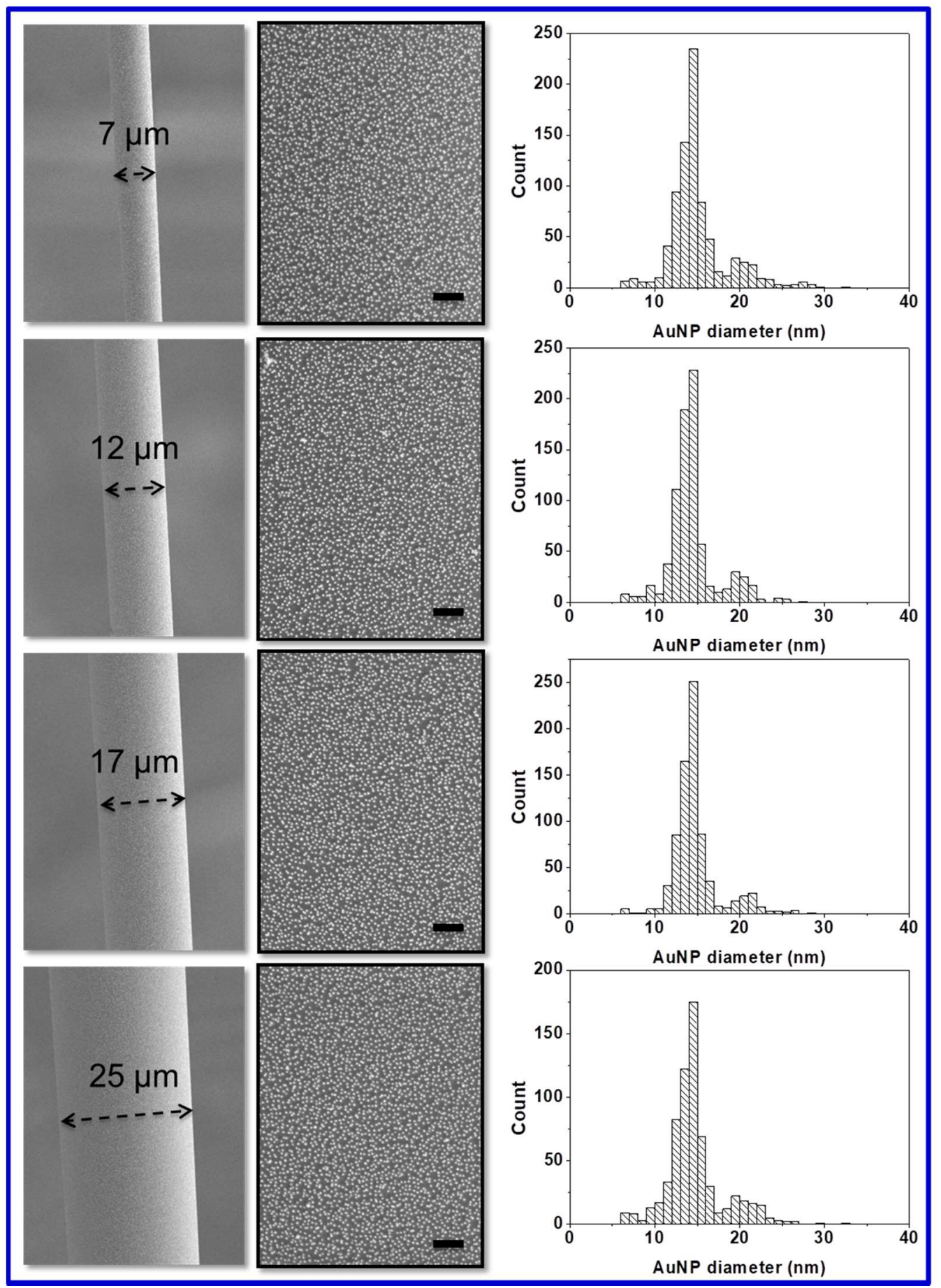

Figure S11. SEM images (low and high resolution, scale bars $200 \mathrm{~nm}$ ) of fibers at the fiber diameters indicated after deposition of 12 nm AuNPs using a PS $_{41}-\mathrm{P}_{4} \mathrm{VP}_{20}$ film template dipcoated at $0.5 \mathrm{~mm} / \mathrm{min}$ from a $20 \mathrm{mg} / \mathrm{mL}$ solution, along with histograms of the AuNP size distribution on the high resolution images. 


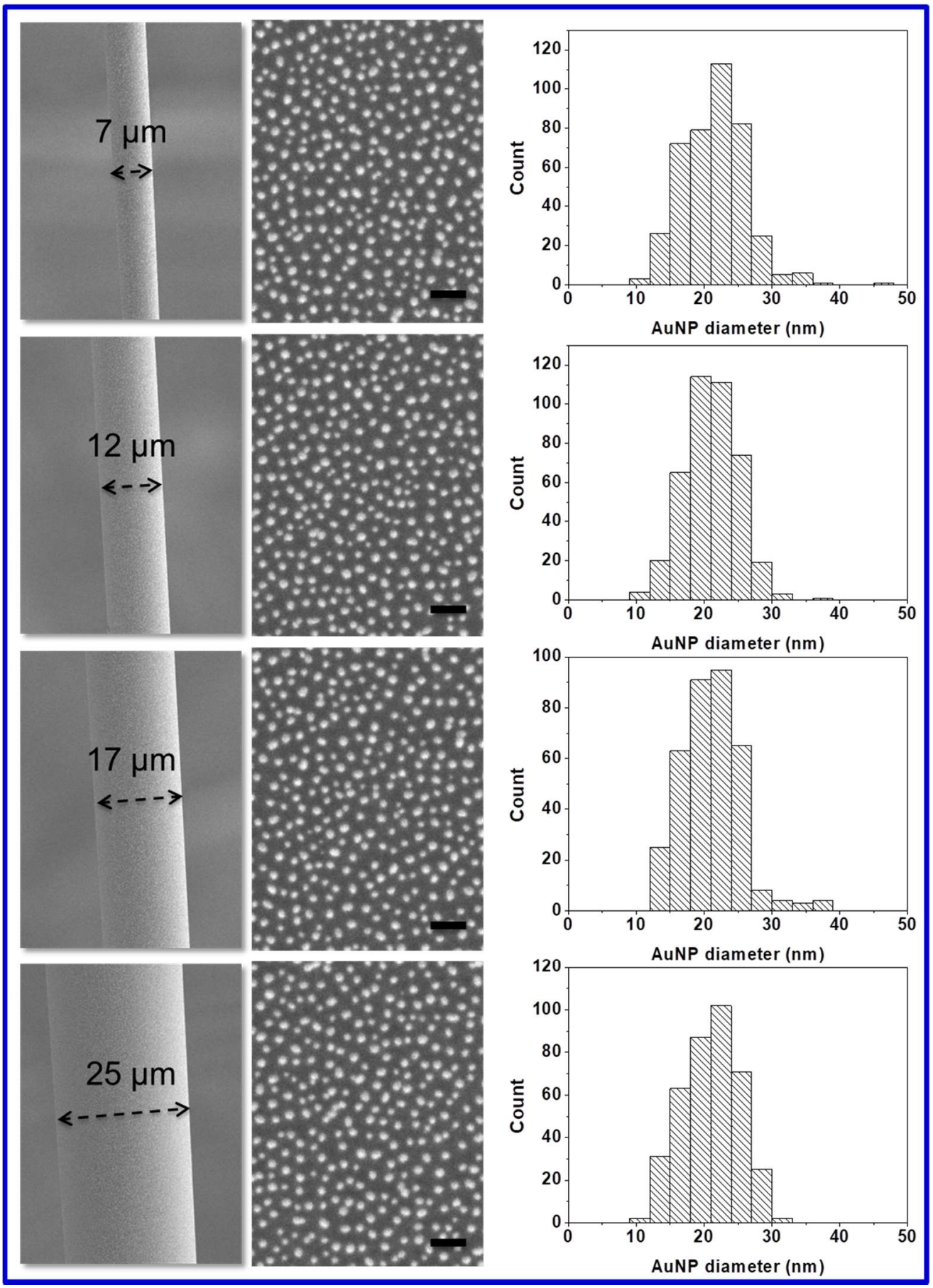

Figure S12. SEM images (low and high resolution, scale bars $100 \mathrm{~nm}$ ) of fibers at the fiber diameters indicated after deposition of 20 nm AuNPs using a $\mathrm{PS}_{41}-\mathrm{P}_{4} \mathrm{VP}_{20}$ film template dipcoated at $80 \mathrm{~mm} / \mathrm{min}$ from a $5 \mathrm{mg} / \mathrm{mL}$ solution, along with histograms of the AuNP size distribution for the high resolution images. 

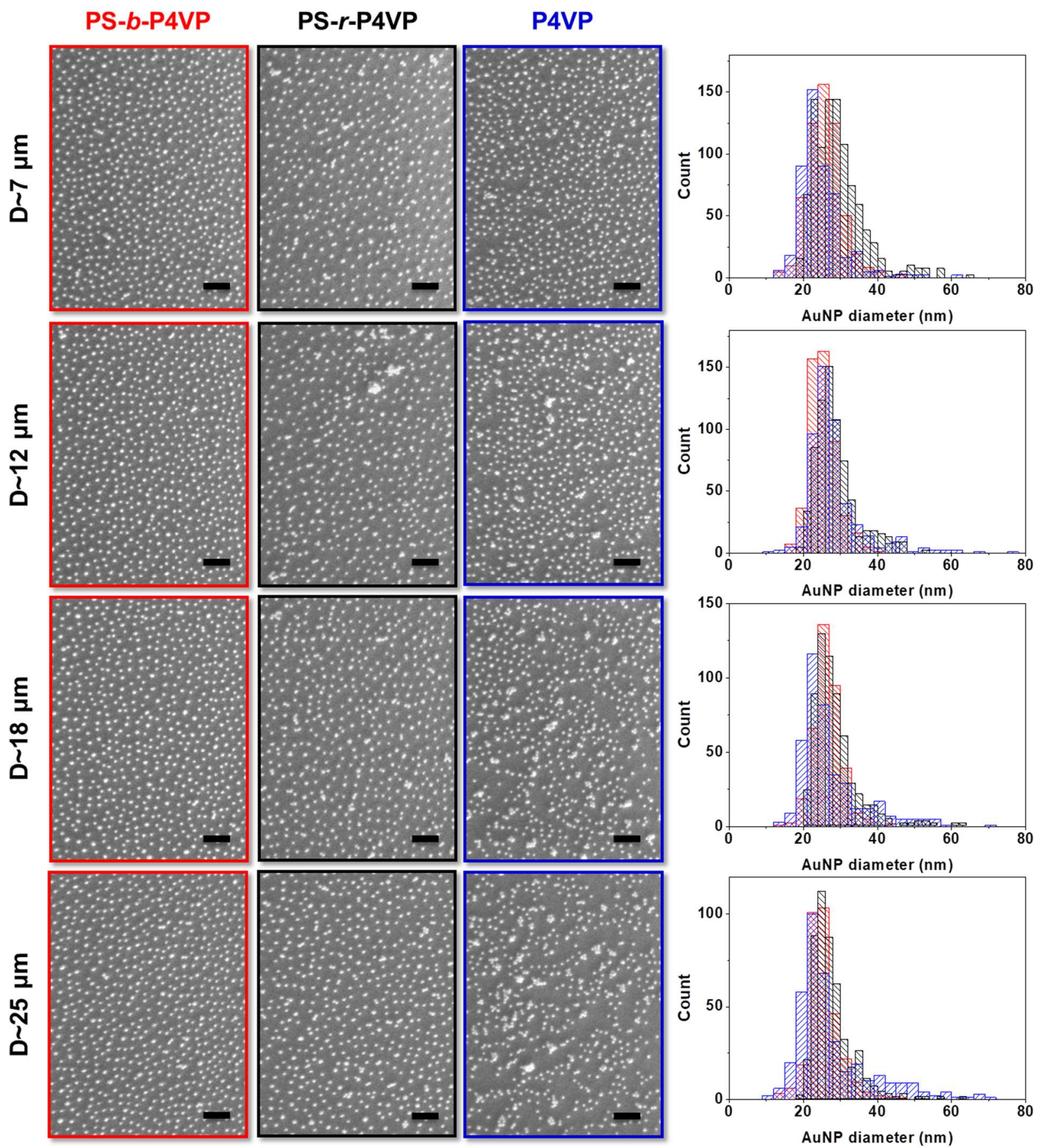

Figure S13. SEM images (scale bars $200 \mathrm{~nm}$ ) of fibers at the fiber diameters, D, indicated in the $1^{\text {st }}$ column after deposition of $32 \mathbf{~ n m}$ AuNPs on a $\mathrm{PS}_{41}-\mathrm{P} 4 \mathrm{VP}_{20}$ brush template ( $2^{\text {nd }}$ column), a PS$r$-P4VP random copolymer template ( $3^{\text {rd }}$ column) and a P4VP homopolymer template ( $4^{\text {th }}$ column). AuNP size distribution histograms ( $5^{\text {th }}$ column) color-coded according to the box around the SEM images. 

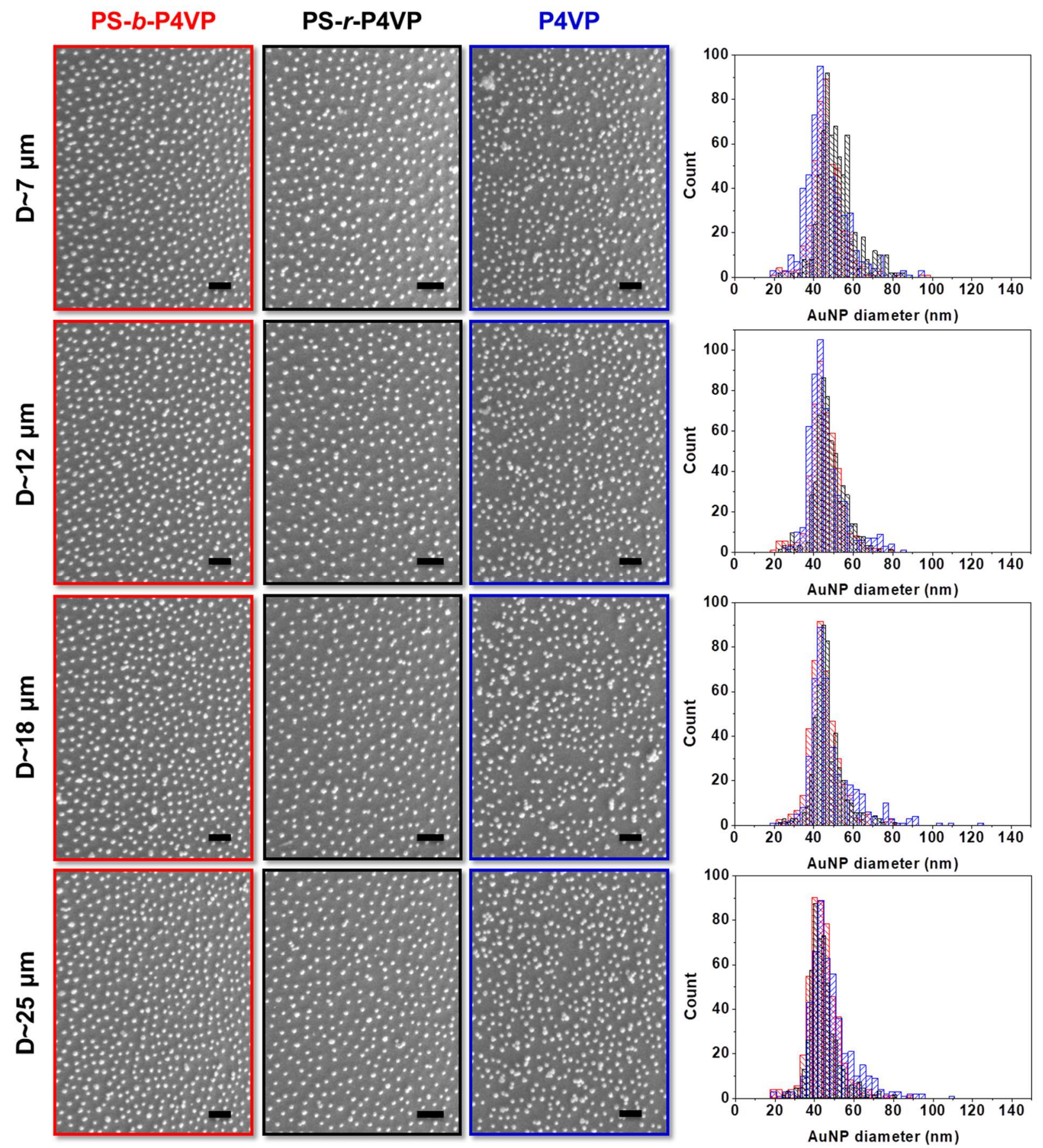

Figure S14. SEM images (scale bar $500 \mathrm{~nm}$ ) of fibers at the fiber diameters, D, indicated in the $1^{\text {st }}$ column after deposition of $\mathbf{5 2} \mathbf{~ n m ~ A u N P s ~ o n ~ a ~} \mathrm{PS}_{41}-\mathrm{P} 4 \mathrm{VP}_{20}$ brush template ( $2^{\text {nd }}$ column), a PS- $r$ P4VP random copolymer template ( $3^{\text {rd }}$ column) and a P4VP homopolymer template ( $4^{\text {th }}$ column). AuNP size distribution histograms ( $5^{\text {th }}$ column) color-coded according to the box around the SEM images. 

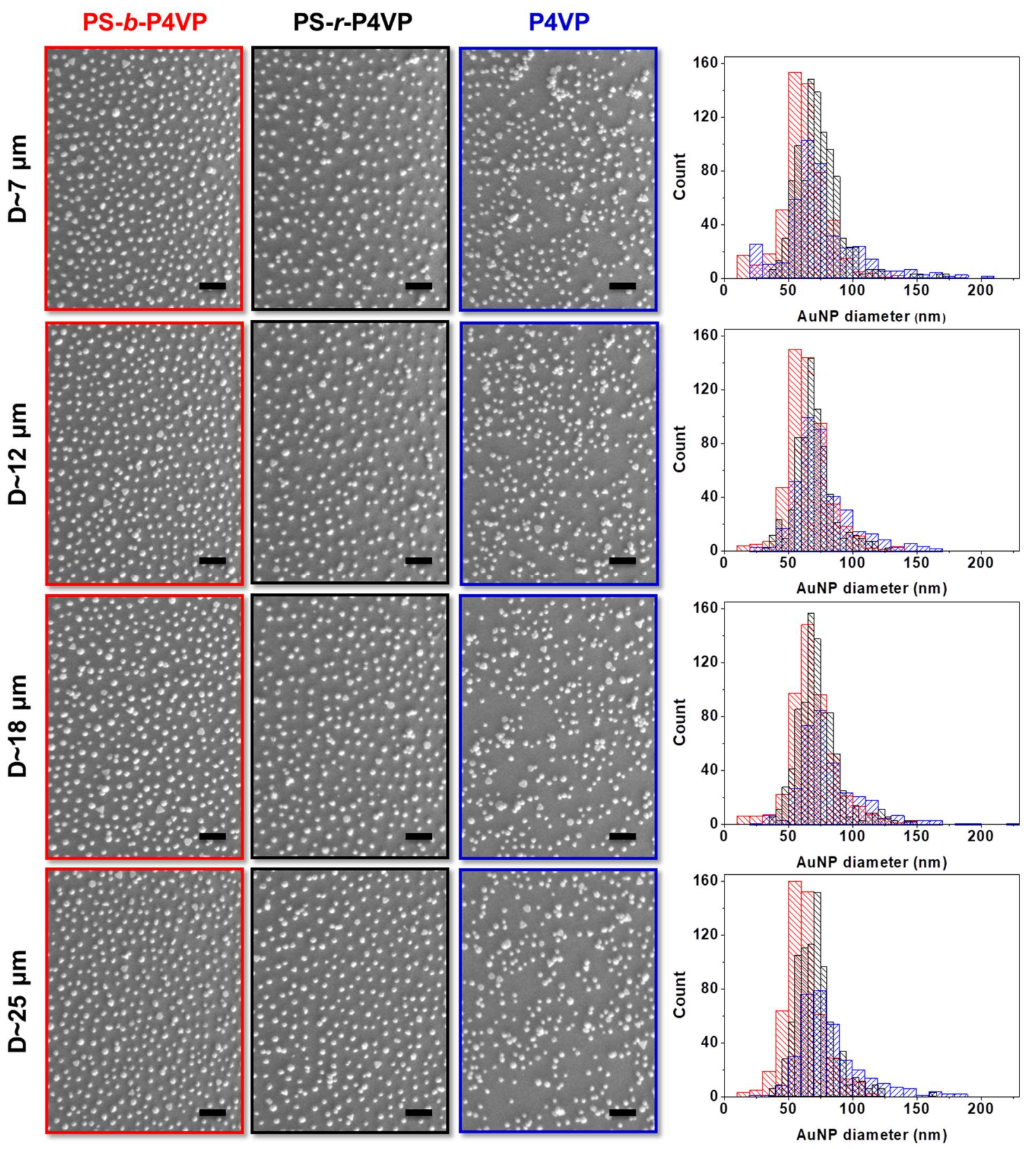

Figure S15. SEM images (scale bar $400 \mathrm{~nm}$ ) of fibers at the fiber diameters, D, indicated in the $1^{\text {st }}$ column after deposition of $\mathbf{7 8} \mathbf{~ n m ~ A u N P s ~ o n ~ a ~} \mathrm{PS}_{41}-\mathrm{P}_{4} \mathrm{VP}_{20}$ brush template (2 ${ }^{\text {nd }}$ column), a PS- $r$ P4VP random copolymer template ( $3^{\text {rd }}$ column) and a P4VP homopolymer template ( $4^{\text {th }}$ column). AuNP size distribution histograms ( $5^{\text {th }}$ column) color-coded according to the box around the SEM images. 


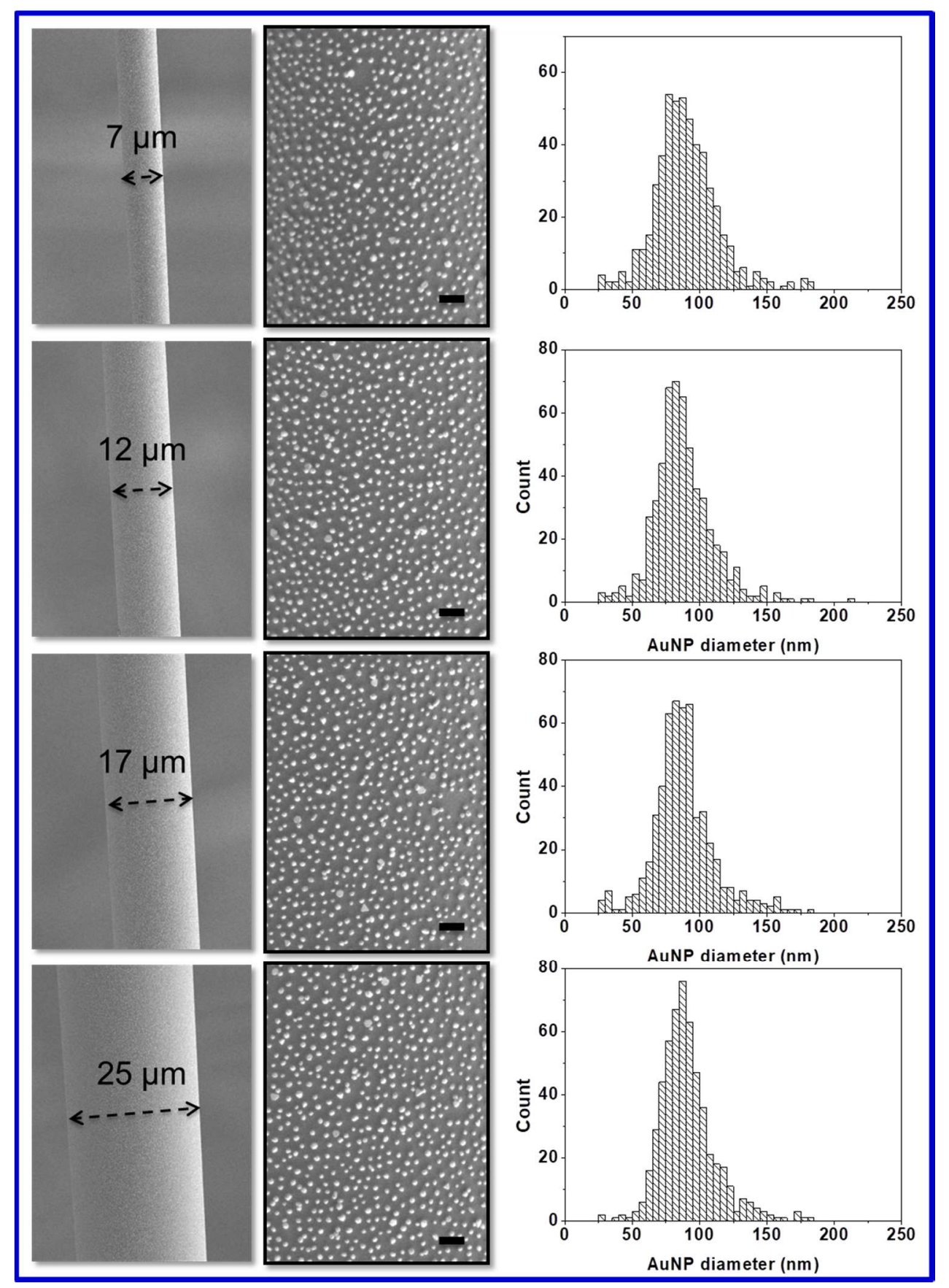

Figure S16. SEM images (low and high resolution, scale bars $500 \mathrm{~nm}$ ) of fibers at the fiber diameters indicated after deposition of $94 \mathbf{~ n m ~ A u N P s ~ u s i n g ~ a ~} \mathrm{PS}_{41}-\mathrm{P}_{4} \mathrm{VP}_{20}$ film template dipcoated at $80 \mathrm{~mm} / \mathrm{min}$ from a $5 \mathrm{mg} / \mathrm{mL}$ solution, along with AuNP size distributions for the high resolution images. 


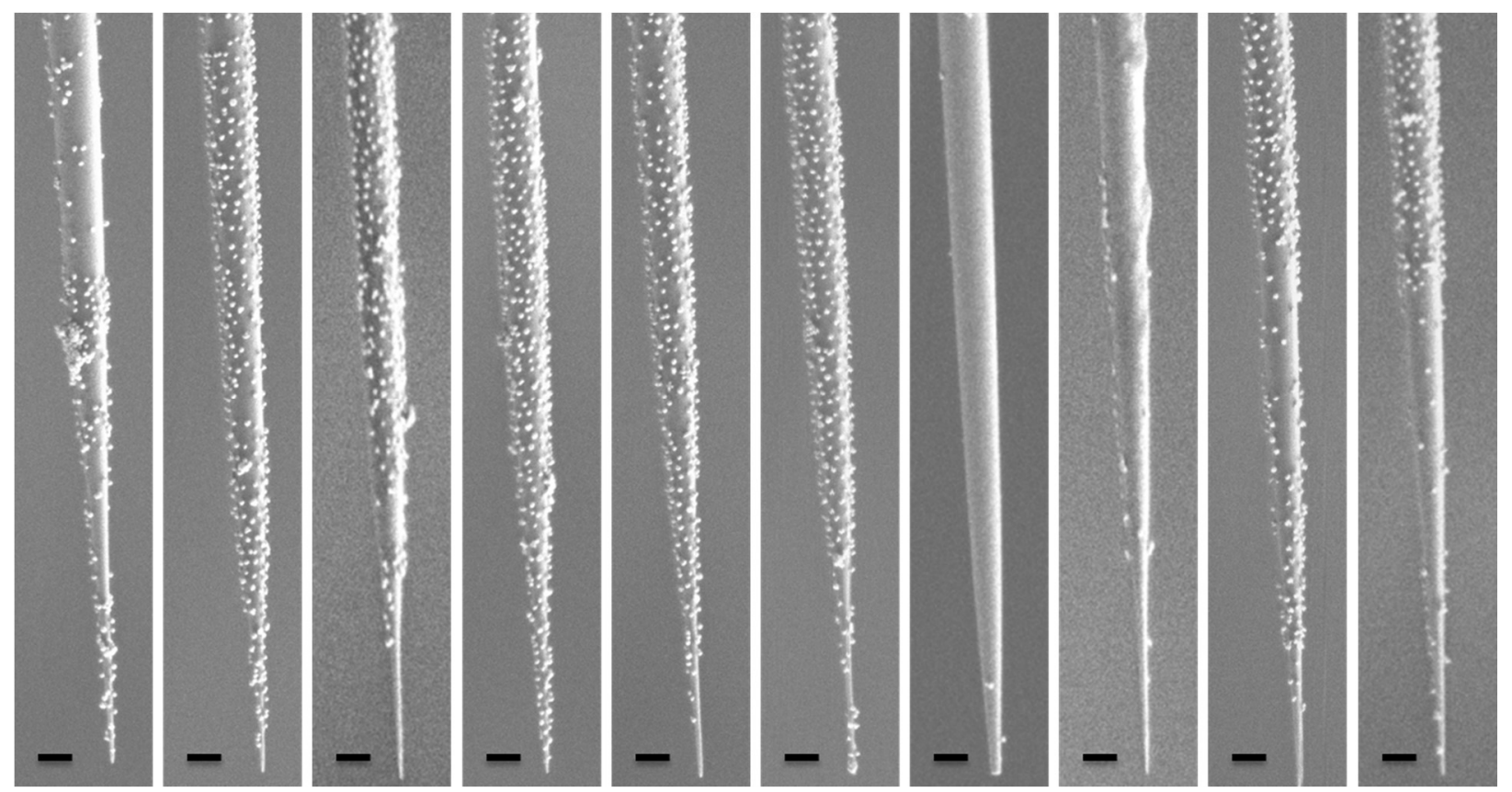

Figure S17. SEM images (scale bars $500 \mathrm{~nm}$ ) of pulled fiber tips coated with a $\mathrm{PS}_{41}-\mathrm{b}-\mathrm{P}_{4} \mathrm{VP}_{20}$ film template onto which $94 \mathbf{n m}$ AuNPs were deposited. 

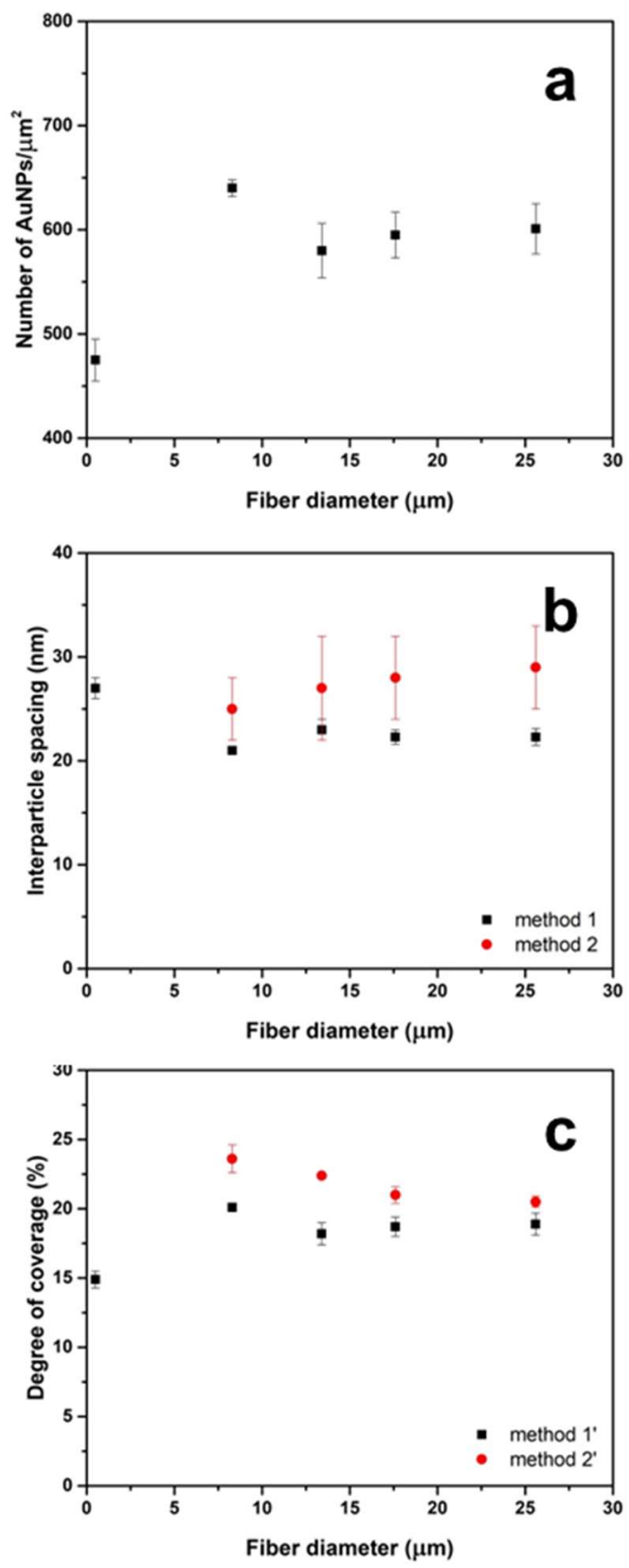

Figure S18. (a) Number density, (b) average interparticle spacing (gap size) and (c) surface coverage, all as a function of fiber diameter, of 20 nm AuNPs deposited on a glass fiber coated with a $\mathrm{PS}_{41}$-b-P4VP 20 brush film obtained from a $0.05 \mathrm{mg} / \mathrm{mL}$ BCP solution concentration. Error bars in (a) and the derived values in (b) and (c) are based on three measurements at slightly different places on the same fiber (five measurements at 200-600 nm diameters for the submicrometer point). See the experimental section in the main text for details about the methods of analysis used in (b) and (c). 

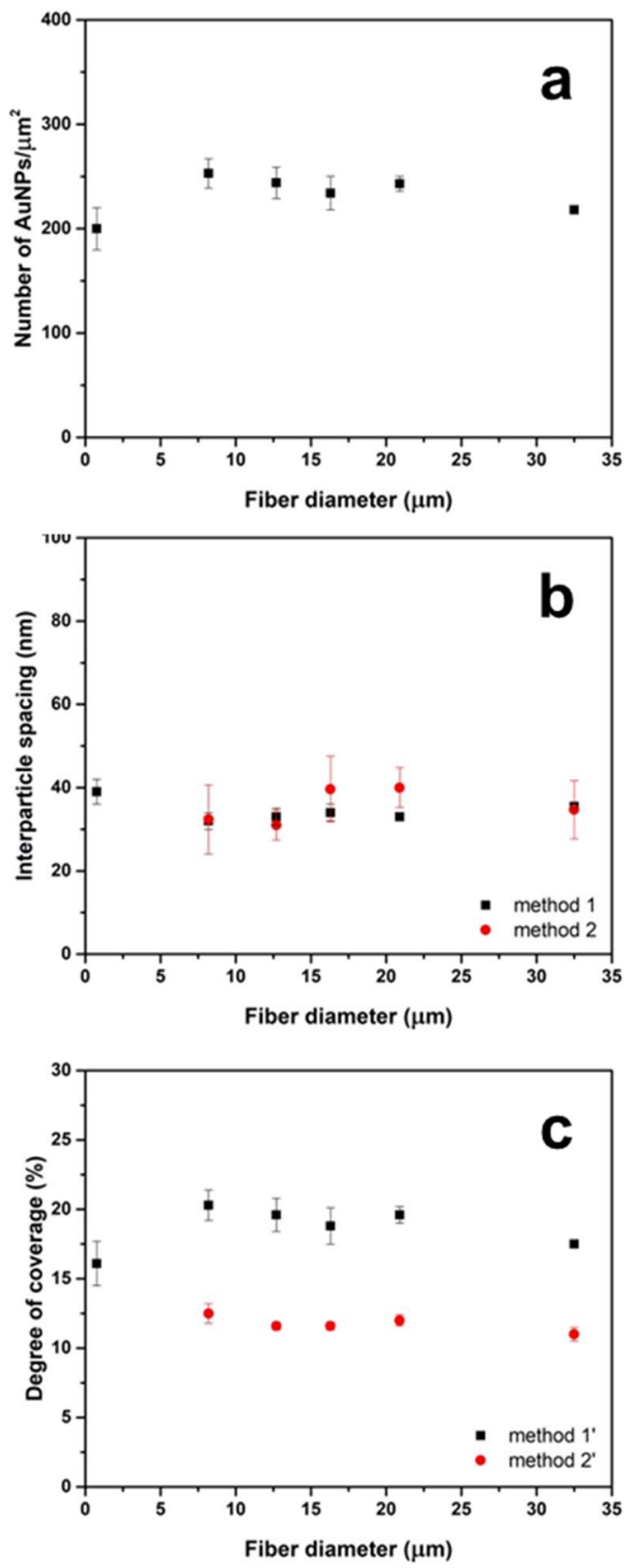

Figure S19. (a) Number density, (b) average interparticle spacing (gap size) and (c) surface coverage, all as a function of fiber diameter, of $\mathbf{3 2} \mathbf{~ n m ~ A u N P s ~ d e p o s i t e d ~ o n ~ a ~ g l a s s ~ f i b e r ~ c o a t e d ~}$ with a $\mathrm{PS}_{41}-\mathrm{b}-\mathrm{P} 4 \mathrm{VP}_{20}$ brush film obtained from a $0.05 \mathrm{mg} / \mathrm{mL}$ BCP solution concentration. Error bars in (a) and the derived values in (b) and (c) are based on measurements at slightly different places on the same fiber (one measurement on three fibers for the submicrometer point. See the experimental section in the main text for details about the methods of analysis used in (b) and (c). 

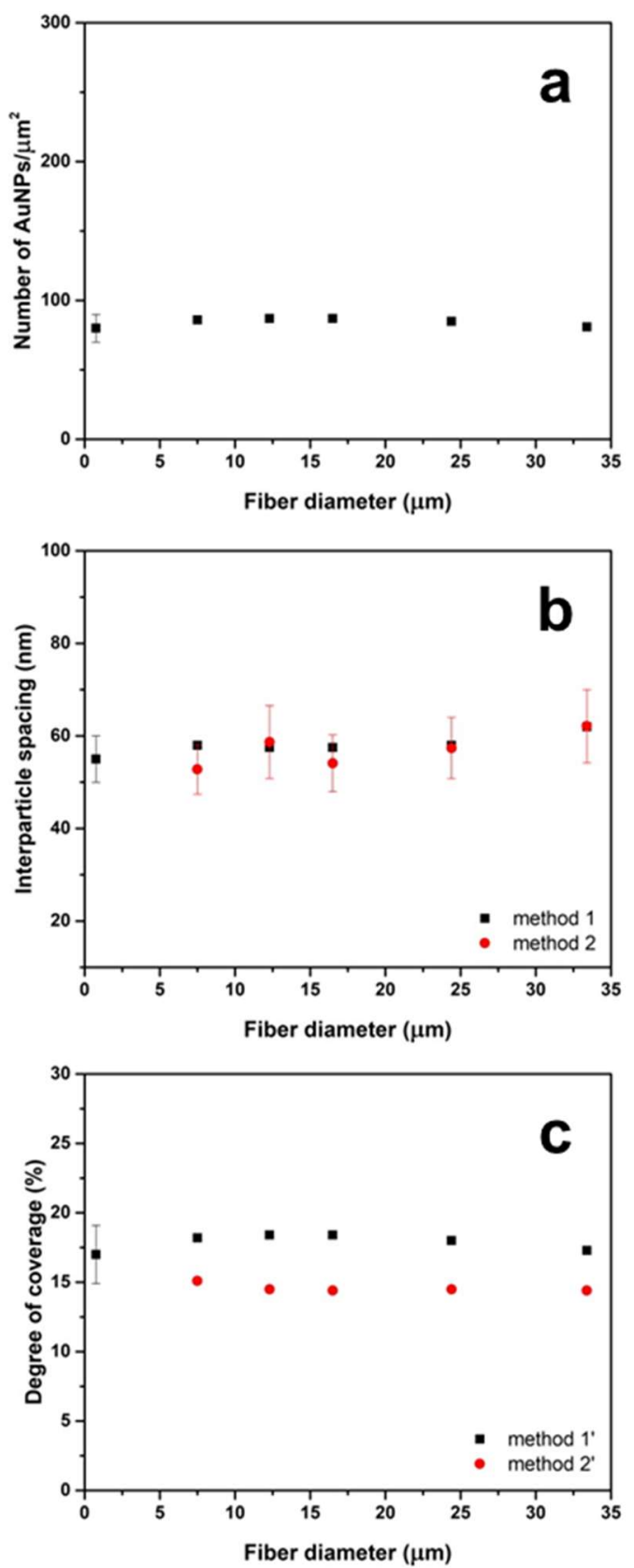

Figure S20. (a) Number density, (b) average interparticle spacing (gap size) and (c) surface coverage, all as a function of fiber diameter, of $\mathbf{5 2} \mathbf{~ n m ~ A u N P s ~ d e p o s i t e d ~ o n ~ a ~ g l a s s ~ f i b e r ~ c o a t e d ~}$ with a $\mathrm{PS}_{41}-\mathrm{b}-\mathrm{P} 4 \mathrm{VP}_{20}$ brush film obtained from a $0.05 \mathrm{mg} / \mathrm{mL} \mathrm{BCP}$ solution concentration (one measurement on one fiber per point due to the larger image size used; three fibers for the submicrometer point). See the experimental section in the main text for details about the methods of analysis used in (b) and (c). 

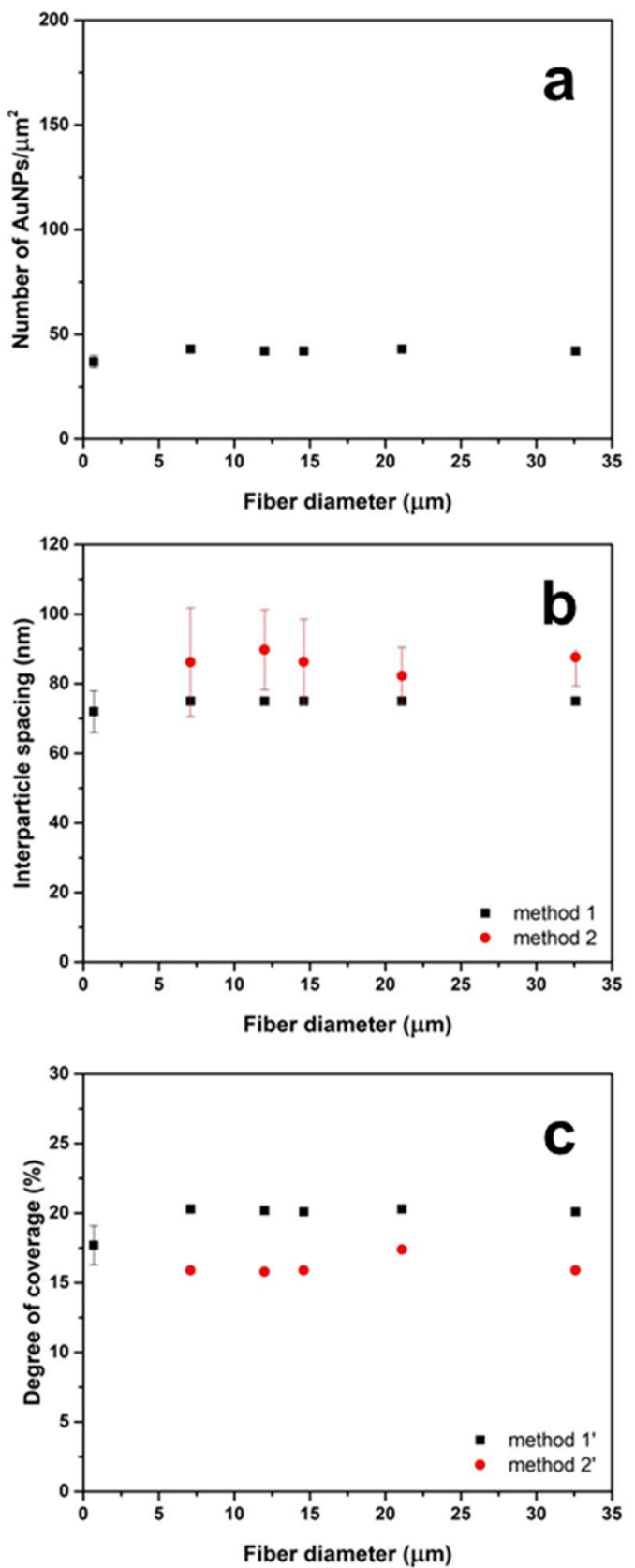

Figure S21. (a) Number density, (b) average interparticle spacing (gap size) and (c) surface coverage, all as a function of fiber diameter, of $78 \mathrm{~nm}$ AuNPs deposited on a glass fiber coated with a $\mathrm{PS}_{41}-\mathrm{b}-\mathrm{P} 4 \mathrm{VP}_{20}$ brush film obtained from a $0.05 \mathrm{mg} / \mathrm{mL} \mathrm{BCP}$ solution concentration (one measurement on one fiber per point due to the larger image size used; three fibers for the submicrometer point). See the experimental section in the main text for details about the methods of analysis used in (b) and (c). 

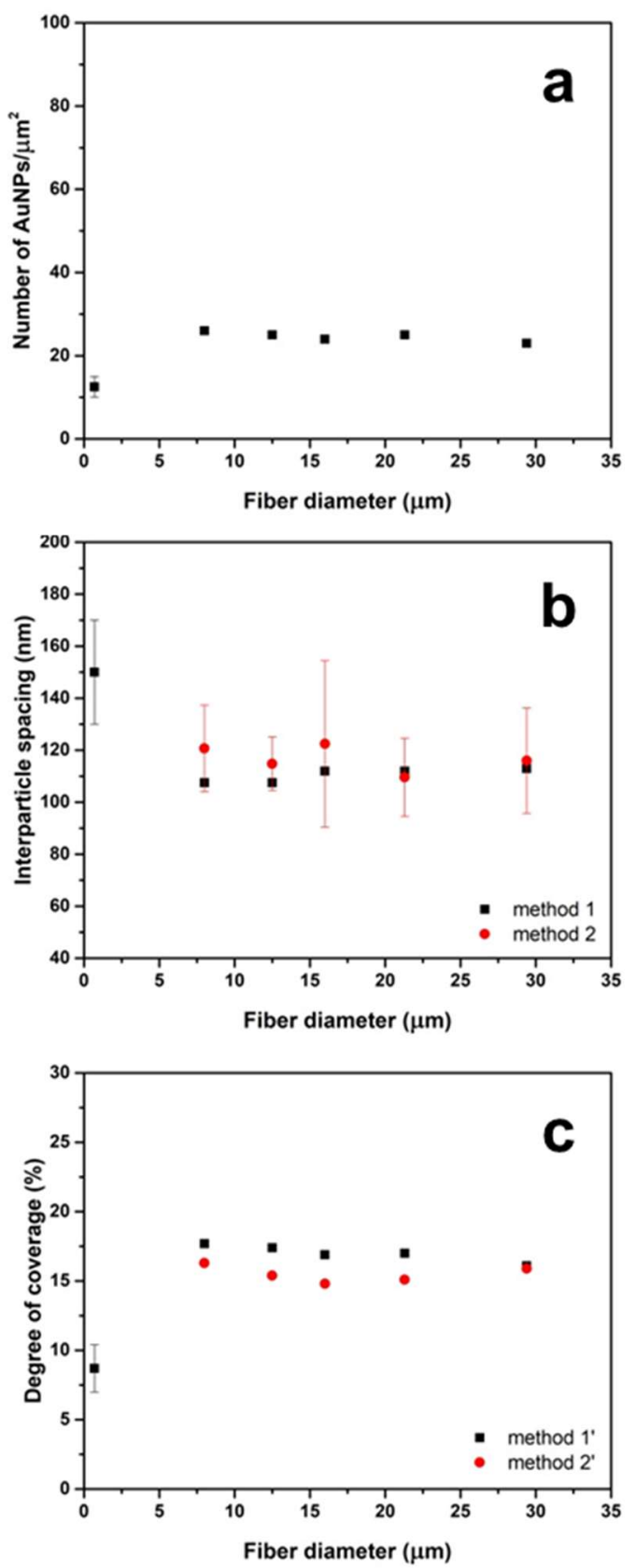

Figure S22. (a) Number density, (b) average interparticle spacing (gap size) and (c) surface coverage, all as a function of fiber diameter, of $94 \mathbf{~ n m ~ A u N P s ~ d e p o s i t e d ~ o n ~ a ~ g l a s s ~ f i b e r ~ c o a t e d ~}$ with a $\mathrm{PS}_{41}-\mathrm{b}-\mathrm{P} 4 \mathrm{VP}_{20}$ brush film obtained from a $0.05 \mathrm{mg} / \mathrm{mL} \mathrm{BCP}$ solution concentration (one measurement on one fiber per point due to the larger image size used; three fibers for the submicrometer point). See the experimental section in the main text for details about the methods of analysis used in (b) and (c). 

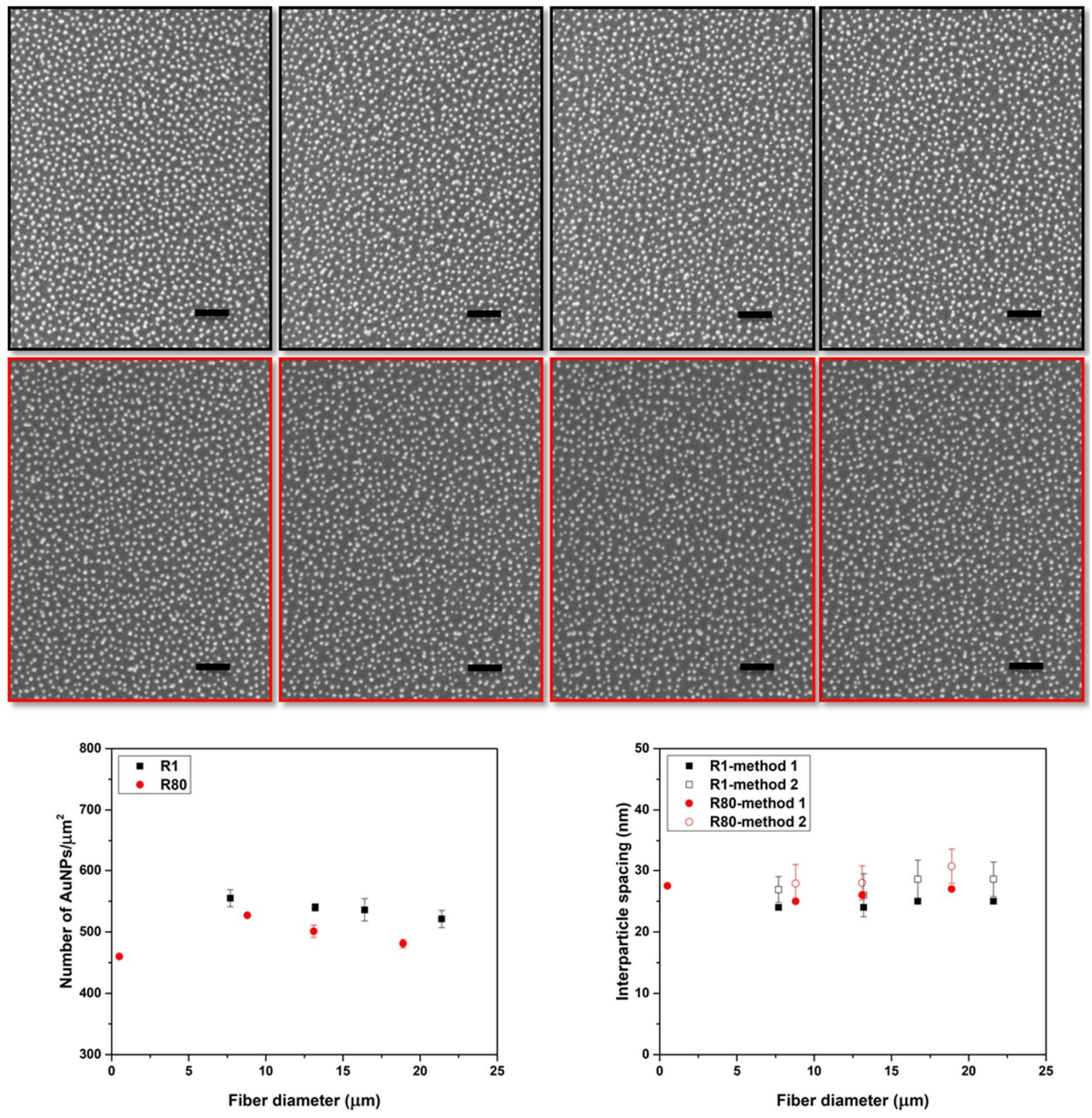

Figure S23. Top: SEM images (scale bars $200 \mathrm{~nm}$, various fiber diameters) of $20 \mathrm{~nm}$ AuNPs deposited on pulled glass fibers coated with a $\mathbf{P S}_{\mathbf{1 2 0}}-\mathbf{b}-\mathbf{P}_{\mathbf{2 0}}$ brush template obtained from a $5 \mathrm{mg} / \mathrm{mL}$ $\mathrm{BCP}$ solution concentration at dip-coating rates of 1 (upper, black) and $80 \mathrm{~mm} / \mathrm{min}$ (lower, red). Bottom: AuNP density avoiding places with significant aggregation (left) and interparticle spacing (gap size, right) as a function of fiber diameter. Error bars are based on three measurements at slightly different places on the same fiber. See the experimental section in the main text for details about methods 1 and 2. 

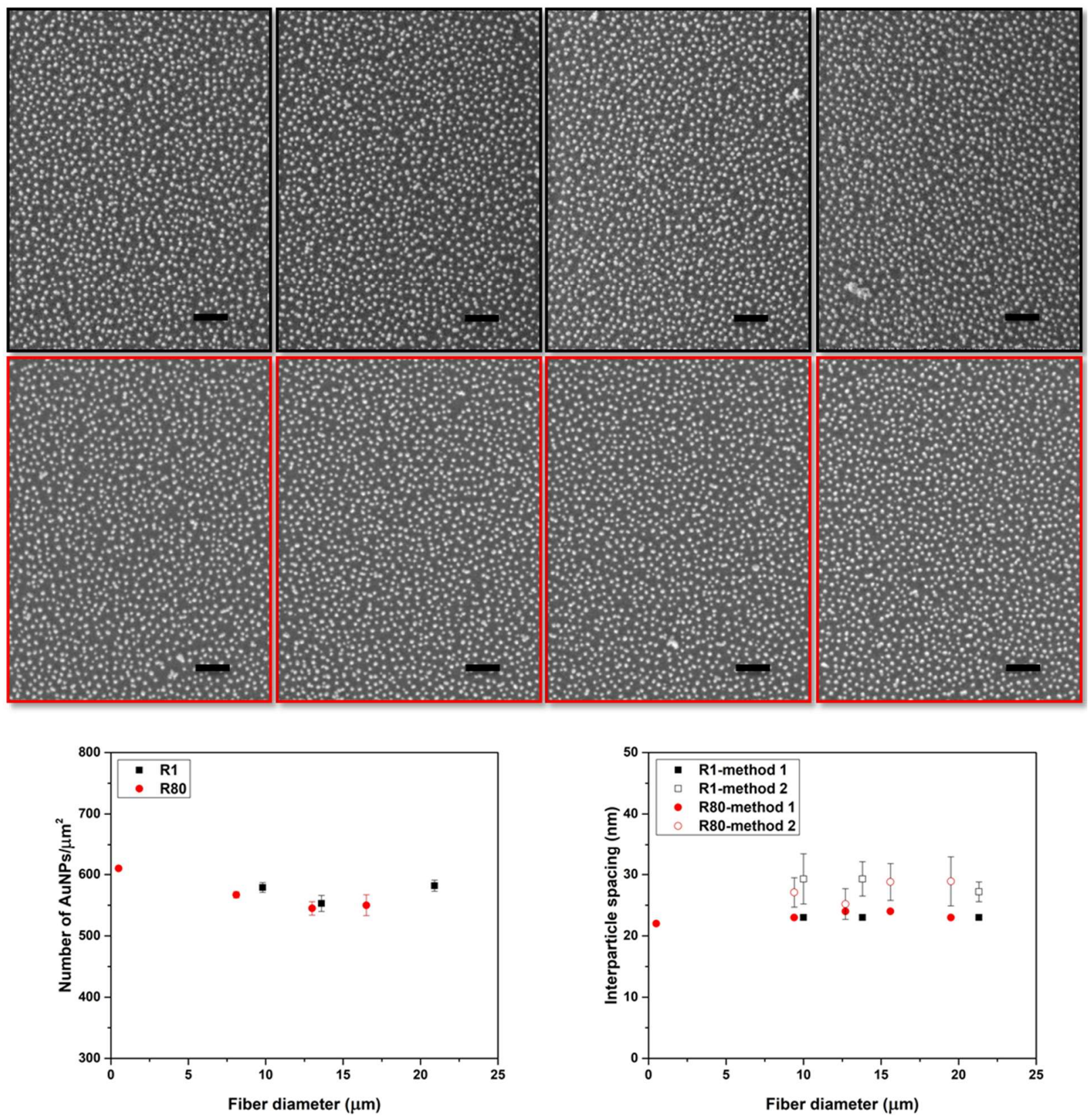

Figure S24. Top: SEM images (scale bars $200 \mathrm{~nm}$, various fiber diameters) of $20 \mathrm{~nm}$ AuNPs deposited on pulled glass fibers coated with a $\mathbf{P S}_{\mathbf{2 5 2}}-\mathbf{b}-\mathbf{P}_{\mathbf{4 3}}$ brush template obtained from a $5 \mathrm{mg} / \mathrm{mL}$ BCP solution concentration at dip-coating rates of 1 (upper, black) and $80 \mathrm{~mm} / \mathrm{min}$ (lower, red). Bottom: AuNP density avoiding places with significant aggregation (left) and interparticle spacing (gap size, right) as a function of fiber diameter. Error bars are based on three measurements at slightly different places on the same fiber. See the experimental section in the main text for details about methods 1 and 2 . 

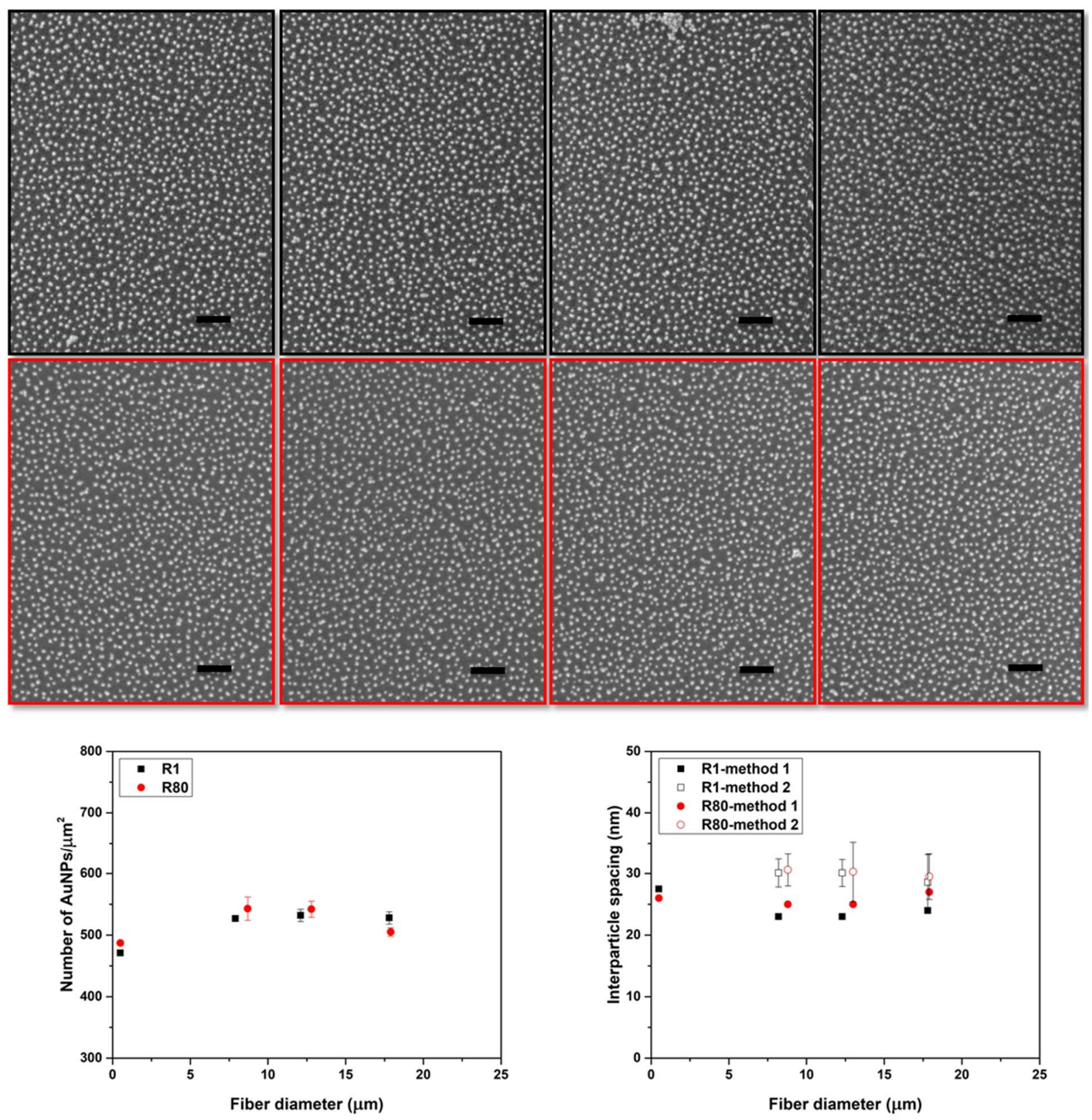

Figure S25. Top: SEM images (scale bars $200 \mathrm{~nm}$, various fiber diameters) of $20 \mathrm{~nm}$ AuNPs deposited on pulled glass fibers coated with a PS84-b-P18 brush template obtained from a $5 \mathrm{mg} / \mathrm{mL}$ BCP solution concentration at dip-coating rates of 1 (upper, black) and $80 \mathrm{~mm} / \mathrm{min}$ (lower, red). Bottom: AuNP density avoiding places with significant aggregation (left) and interparticle spacing (gap size, right) as a function of fiber diameter. Error bars are based on three measurements at slightly different places on the same fiber. See the experimental section in the main text for details about methods 1 and 2 . 

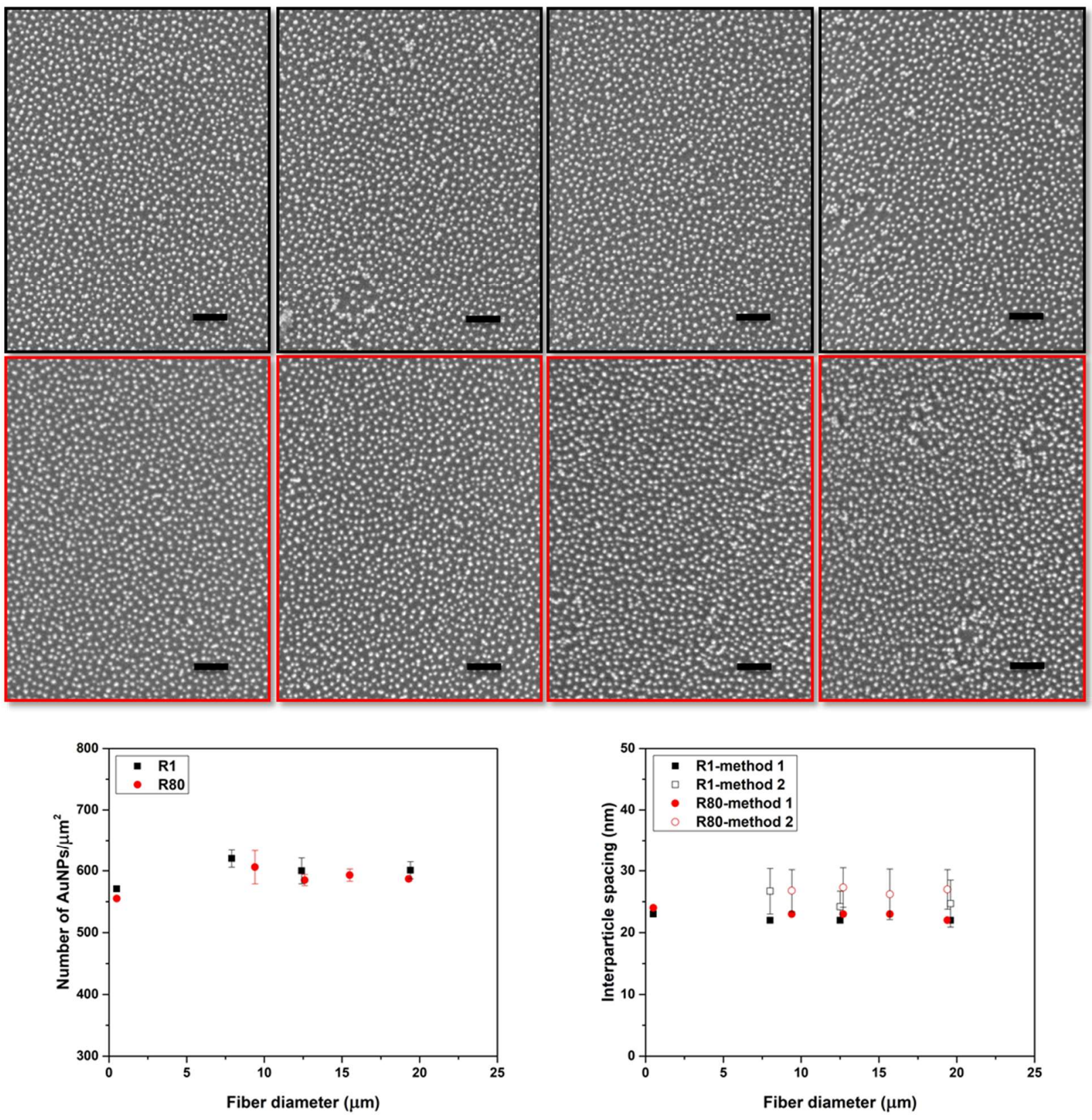

Figure S26. Top: SEM images (scale bars $200 \mathrm{~nm}$, various fiber diameters) of $20 \mathrm{~nm}$ AuNPs deposited on pulled glass fibers coated with a $\mathbf{P S}_{72}-\mathbf{b}-\mathbf{P}_{35}$ brush template obtained from a $5 \mathrm{mg} / \mathrm{mL}$ BCP solution concentration at dip-coating rates of 1 (upper, black) and $80 \mathrm{~mm} / \mathrm{min}$ (lower, red). Bottom: AuNP density avoiding places with significant aggregation (left) and interparticle spacing (gap size, right) as a function of fiber diameter. Error bars are based on three measurements at slightly different places on the same fiber. See the experimental section in the main text for details about methods 1 and 2. 

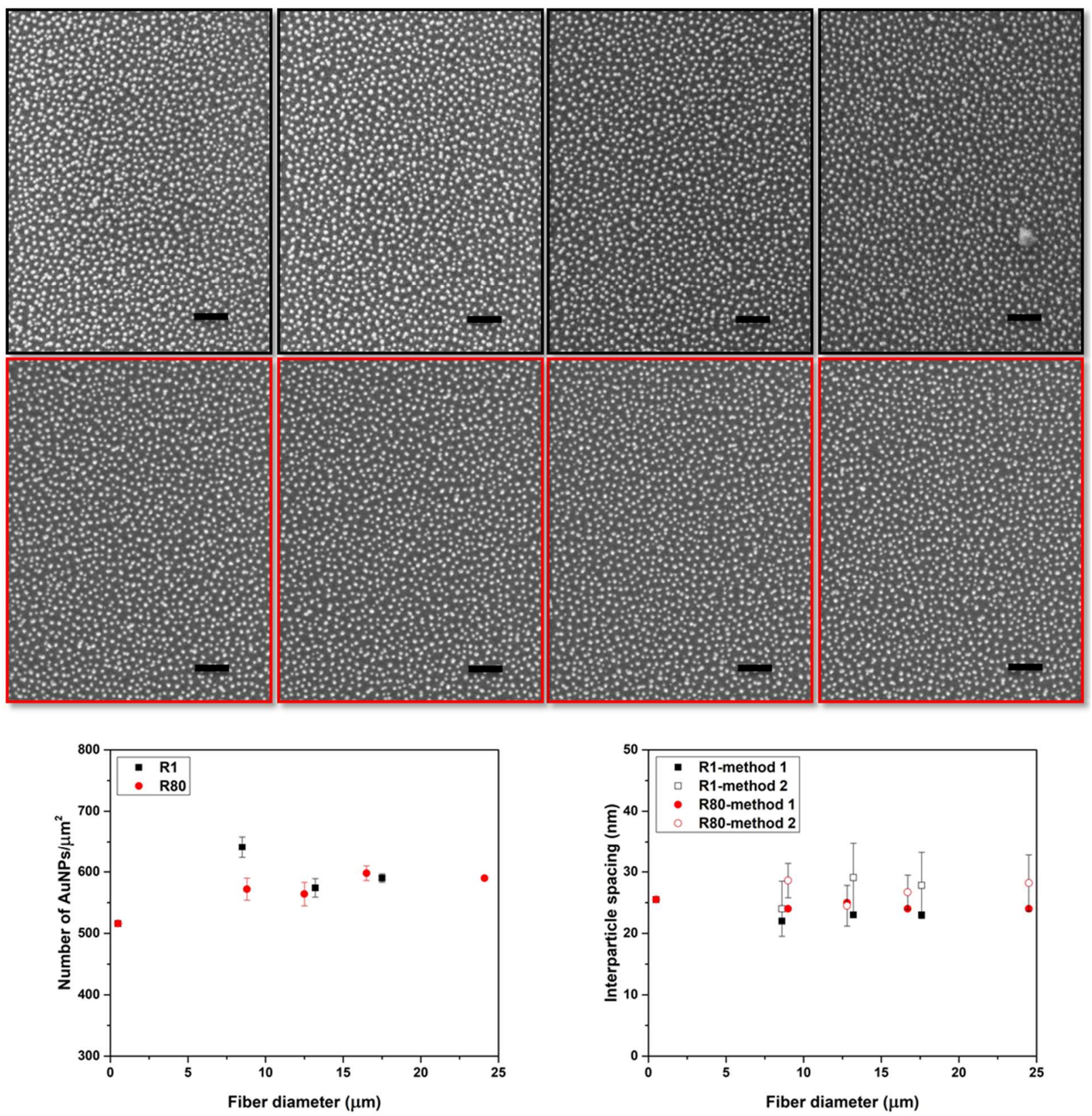

Figure S27. Top: SEM images (scale bars $200 \mathrm{~nm}$, various fiber diameters) of $20 \mathrm{~nm}$ AuNPs deposited on pulled glass fibers coated with a PS41-b-P20 brush template obtained from a $5 \mathrm{mg} / \mathrm{mL}$ BCP solution concentration at dip-coating rates of 1 (upper, black) and $80 \mathrm{~mm} / \mathrm{min}$ (lower, red). Bottom: AuNP density avoiding places with significant aggregation (left) and interparticle spacing (gap size, right) as a function of fiber diameter. Error bars are based on three measurements at slightly different places on the same fiber. See the experimental section in the main text for details about methods 1 and 2 . 

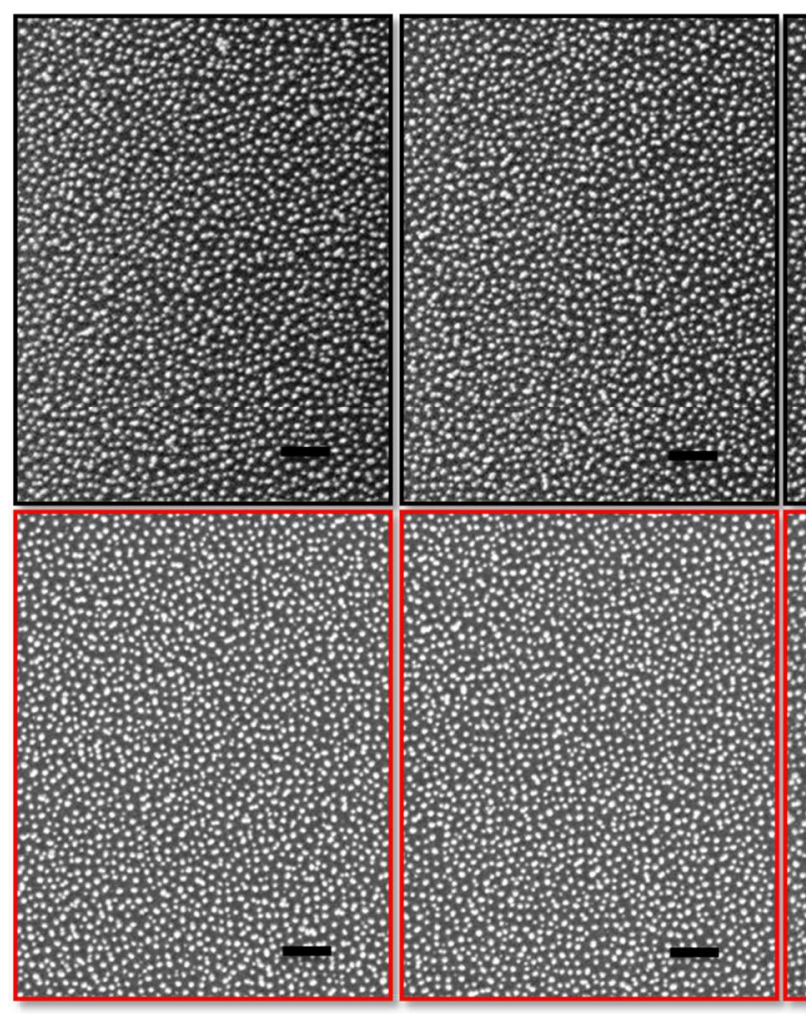
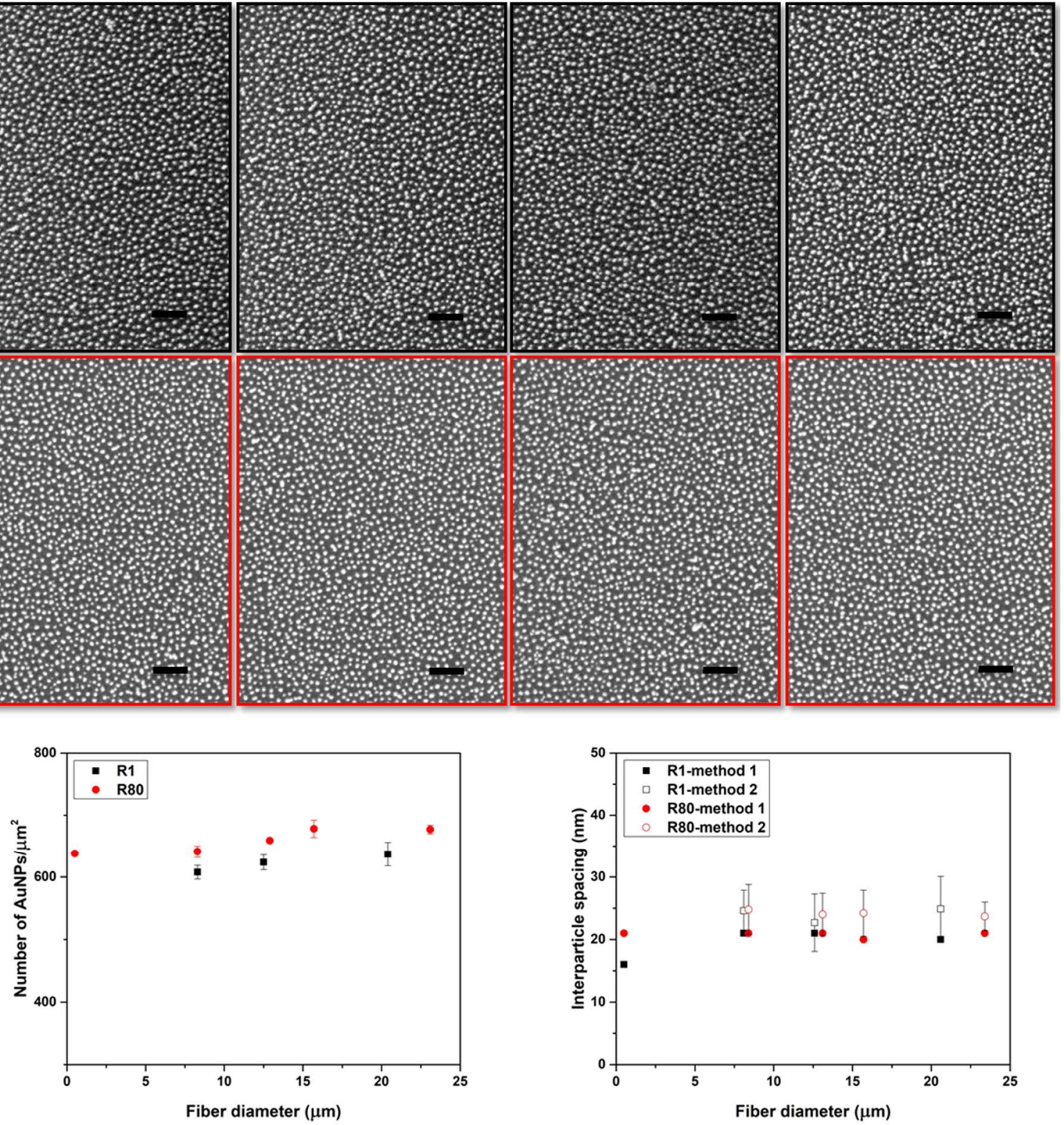

Figure S28. Top: SEM images (scale bars $200 \mathrm{~nm}$, various fiber diameters) of $20 \mathrm{~nm}$ AuNPs deposited on pulled glass fibers coated with a $\mathbf{P S}_{\mathbf{2 0}} \mathbf{- b}-\mathbf{P}_{\mathbf{2}}$ brush template obtained from a $5 \mathrm{mg} / \mathrm{mL}$ $\mathrm{BCP}$ solution concentration at dip-coating rates of 1 (upper, black) and $80 \mathrm{~mm} / \mathrm{min}$ (lower, red). Bottom: AuNP density avoiding places with significant aggregation (left) and interparticle spacing (gap size, right) as a function of fiber diameter. See the experimental section in the main text for details about methods 1 and 2 . 


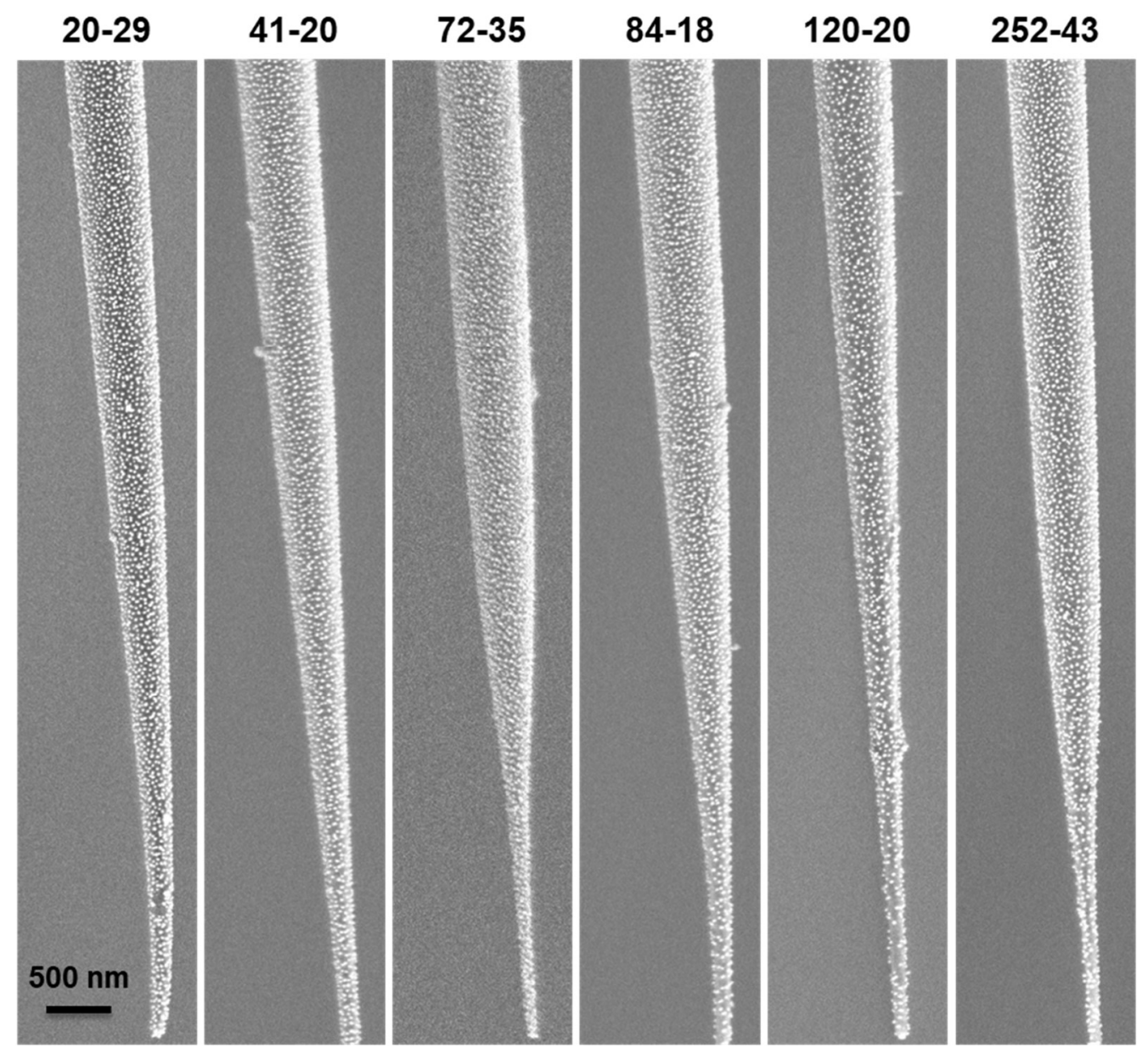

Figure S29. SEM images of $20 \mathrm{~nm}$ AuNPs deposited on nanofibers coated with PS-b-P4VP brush layers, with the block molecular weights indicated in $\mathrm{kg} / \mathrm{mol}$ above each image. The brush-layer templates were dip-coated at $80 \mathrm{~mm} / \mathrm{min}$ from $5 \mathrm{mg} / \mathrm{mL}$ THF solutions. 
a

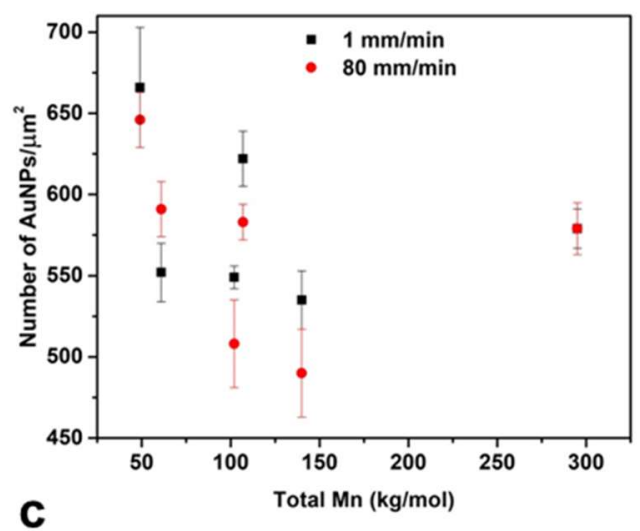

C
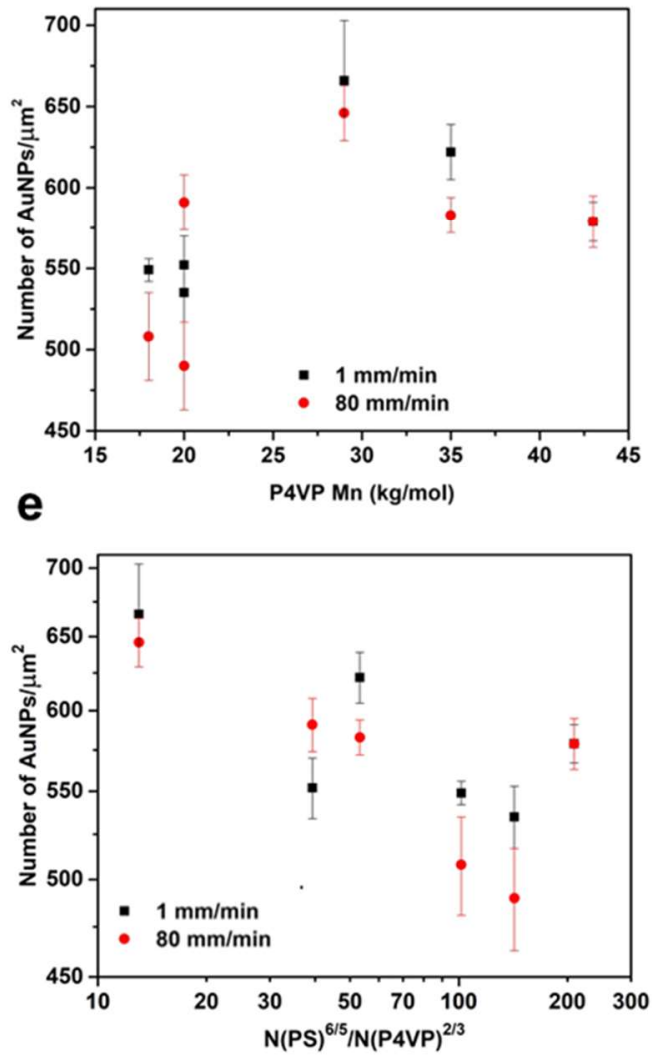

b
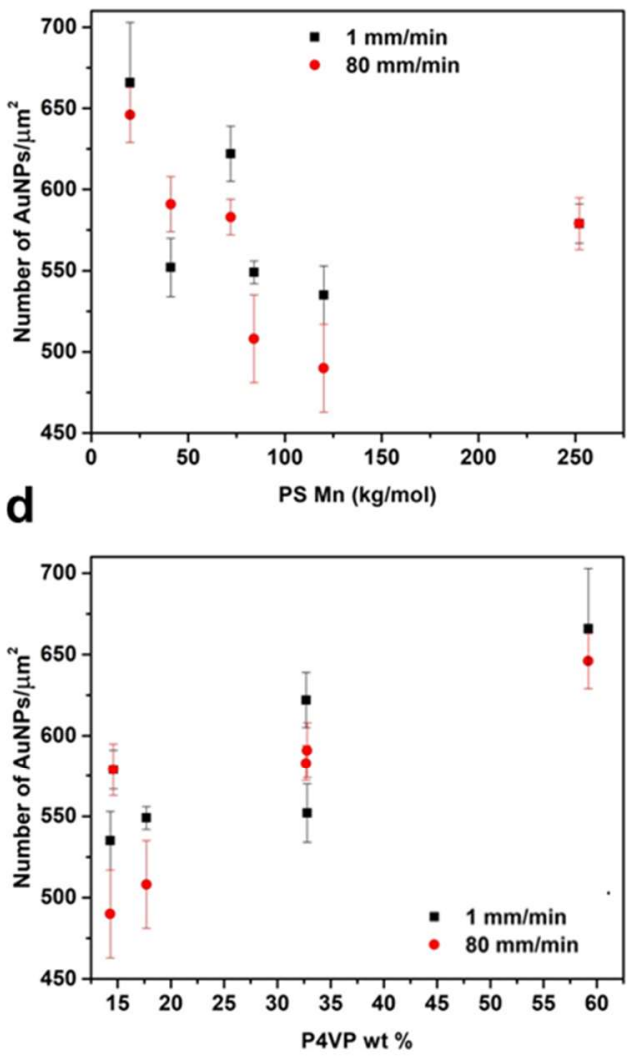

Figure S30. AuNP density of $20 \mathrm{~nm}$ AuNPs deposited on pulled glass fibers coated with BCP brush templates of various block compositions as a function of (a) total BCP molecular weight, (b) PS molecular weight, (c) P4VP molecular weight, and (d) weight percent P4VP. As further explained in the main text, graph (e) follows an analysis by Parsonage et al., ${ }^{3}$ where the $\mathrm{x}$-axis parameter represents a $\mathrm{BCP}$ asymmetry ratio ( $\mathrm{N}$ referring to the block degree of polymerization); values up to about 70-100 reflect moderate asymmetry. The BCP brush templates were dip-coated at $1 \mathrm{~mm} / \mathrm{min}$ (black) and $80 \mathrm{~mm} / \mathrm{min}$ (red) from $5 \mathrm{mg} / \mathrm{mL}$ THF solutions. Error bars represent standard deviations of 4-5 different fiber diameters (shown in Figures S23-S28). 


\section{References}

1. Haiss, W.; Thanh, N. T. K.; Aveyard, J.; Fernig, D. G., Determination of Size and Concentration of Gold Nanoparticles from UV-Vis Spectra. Anal. Chem. 2007, 79, 42154221 .

2. Roland, S.; Gaspard, D.; Prud'homme, R. E.; Bazuin, C. G., Morphology Evolution in Slowly Dip-Coated Supramolecular PS-b-P4VP Thin Films. Macromolecules 2012, 45, 5463-5476.

3. Parsonage, E.; Tirrell, M.; Watanabe, H.; Nuzzo, R. G., Adsorption of Poly(2-vinylpyridine)Poly(styrene) Block Copolymers from Toluene Solutions. Macromolecules 1991, 24, 19871995. 